\title{
Working
}

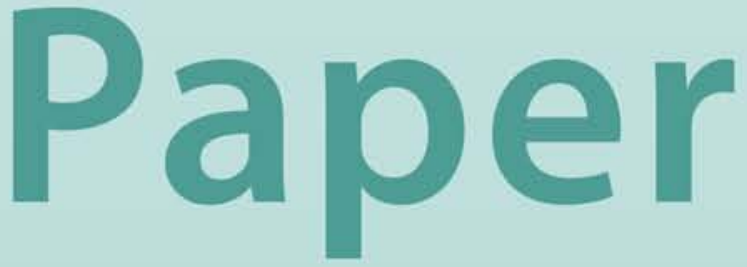




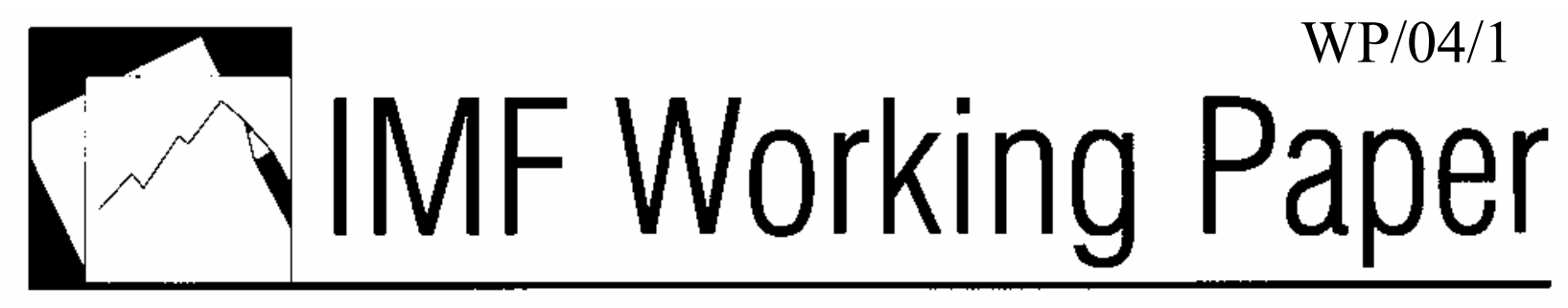

The Gains from International Monetary

Cooperation Revisited

Ivan Tchakarov

INTERNATIONAL MONETARY FUND 


\title{
IMF Working Paper
}

Research Department

\section{The Gains from International Monetary Cooperation Revisited}

\author{
Prepared by Ivan Tchakarov ${ }^{1}$ \\ Authorized for distribution by Tamim A. Bayoumi
}

January 2004

\begin{abstract}
This Working Paper should not be reported as representing views of the IMF. The views expressed in this Working Paper are those of the author(s) and do not necessarily represent those of the IMF or IMF policy. Working Papers describe research in progress by the author(s) and are published to elicit comments and to further debate.
\end{abstract}

This paper examines the issue of whether countries can improve their welfare by coordinating macroeconomic policies. The main purpose is to compute the gains from international monetary cooperation as the difference between the steady state consumption levels associated with the Nash and the cooperative outcomes of the game in which monetary authorities pursue active monetary policy. A numerical second-order approximation makes the solution of the model possible. Contrary to Obstfeld and Rogoff (2002), who claim that the gains from international cooperation in monetary policy are negligible, the paper finds that they could be very significant and reach as high as 2.2 percent of steady state consumption. This suggests that individual countries could experience significant welfare losses if they concentrate only on domestic stabilization policies.

JEL Classification Numbers: F41, F42

Keywords: monetary policy coordination, second-order approximation Author's E-Mail Addresses: itchakarov@imf.org

\footnotetext{
${ }^{1}$ The author is an Economist in the IMF Research Department. He thanks Paul Bergin and participants at the Macro Brown Bag Seminar at UC Davis. All remaining errors are the author's.
} 
I. Introduction

II. A General Two-country Model ...................................................................

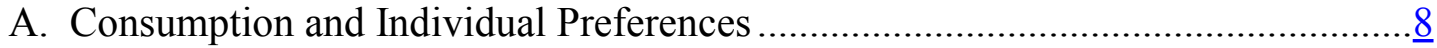

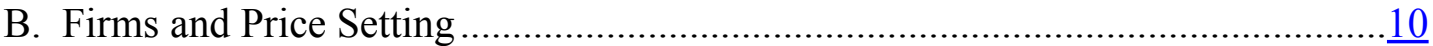

C. Households and Wage Setting...............................................................

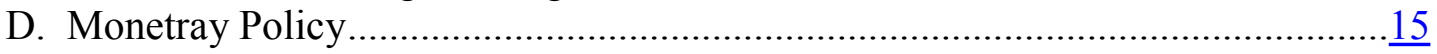

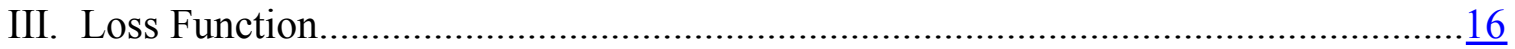

IV. Optimal Cooperative and Nash Monetary Policy …......................................

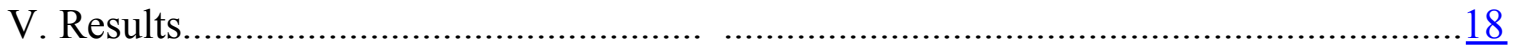

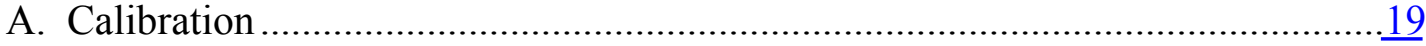

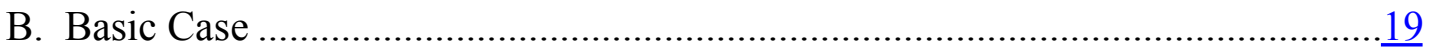

C. Wage Case .............................................................................................. $\frac{20}{20}$

D. Non-traded Goods Case...............................................................................

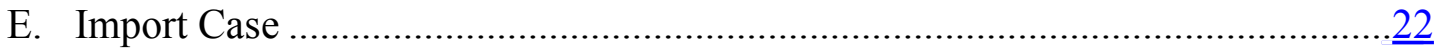

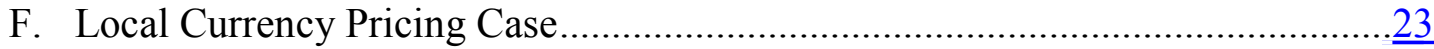

G. Gains from Coordination with Global Shocks ............................................. $\frac{23}{24}$

H. Gains from Coordination with Incomplete Asset Markets................................24

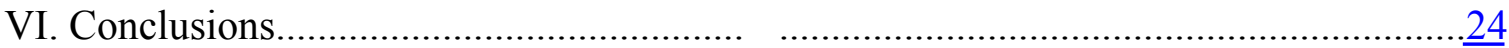

Tables:

1. Gains from Cooperation in the Basic Case for Different Values of $m u$..................

2. Gains from Cooperation in the Basic Case for Different Values of rho and the Inverse of the Interest Elasticity of Real Money Balances (with $m u$ equal to one).. 27

3. Gains from Cooperation in the Basic Case for Different Values of rho and the Inverse of the Interest Elasticity of Real Money Balances (with $m u$ equal to six)... $\underline{28}$

4. Gains from Cooperation in the Wage Case.......................................................29

5. Gains from Cooperation in the Nontraded Goods Case.......................................

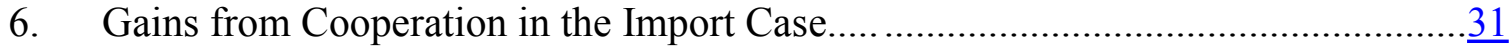

7. Gains from Cooperation in the Local Currency Pricing Case...............................

8. Gains from Cooperation with Global Shocks ...................................................... $\frac{33}{34}$

9. Gains from Cooperation with Incomplete Asset Markets.......................................

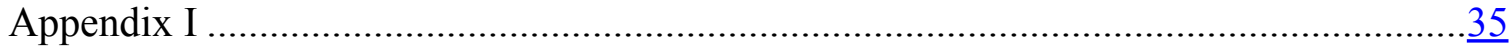

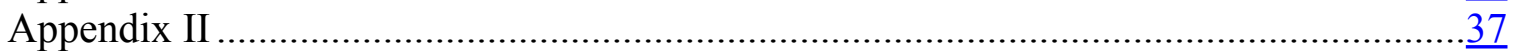

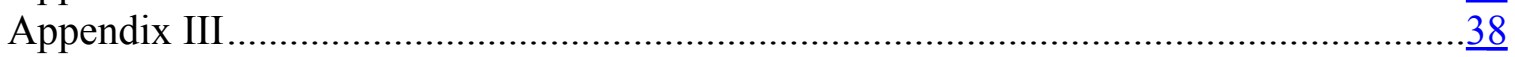

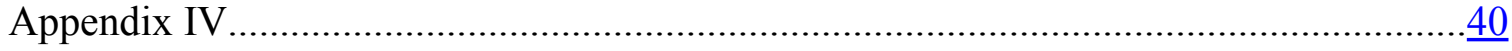

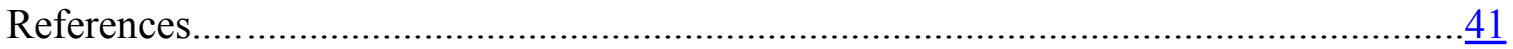




\section{INTRODUCTION}

The question of coordinating macroeconomic policies has been very important in international policy analyses. Cooper (1968) was the frst to recognize the importance of interdependence for international policy analysis. In a world where the actions in one country can spill over to other countries, it is clear that cooperation could potentially raise welfare. In this respect, it is reasonable to assume that with the increase not only in the volume but also in the variety of intercountry linkages the scope for cooperation will also grow. This idea has been seriously challenged by Obstfeld and Rogoff (2002), who develop a second-generation ${ }^{2}$ model of international monetary cooperation based on $\mathrm{frm}$ microfoundations. They claim that any benef ts from monetary policy coordination that might arise in a two-country world will be easily swamped by the gains from pursuing stabilization policies within the individual countries. ${ }^{3}$ Of course, Obstfeld and Rogoff's conclusion appears to depend on the simplifying assumptions they make to render their model analytically solvable. Even though some authors ${ }^{4}$ have tried to respond to Obstfeld and Rogoff by providing examples in which gains could be signif cant from a theoretical point of view, a solid quantitative investigation of the matter has not been available ${ }^{5}$.

This paper tries to address the issue of international monetary coordination by taking advantage of some very recent developments in the New Open Economy Macroeconomics (NOEM) literature. A two-country dynamic general equilibrium model with nominal price and wage rigidities and monopolistic competition is built. Because the model is constructed with microeconomic foundations, it provides the utility function as a natural criterion for evaluating the welfare implications of different policies. This is used to measure welfare under two scenarios. One is where each country tries to maximize its own agents' welfare taking the actions of the other country as given. The other is where a coordinated policymaker tries to maximize the welfare of both countries together.

The method of welfare evaluation is better than that employed in past studies. The old literature, which is reviewed in some detail in the next section, had to rely on ad hoc loss functions rather than utility functions, because the models used were not built on a utility theoretic framework.

In addition, this work also constitutes an improvement on the recent NOEM literature. While the latter uses the utility function, it evaluates it using only a f rst-order approximation to the micro-founded model. This means that no consideration has been made about all the effects

2 Credit for the distinction between frst- and second-generation models of international cooperation is given to Canzoneri, Cumby, and Diba (2002).

3 An early example of when cooperation might even be counterproductive is provided by Rogoff (1985).

4 See for example Benigno and Benigno (2002, 2003a, 2003b), Clarida and Gali (2002) and Canzoneri, Cumby, and Diba (2002).

5 The only exception is Sutherland (2002b), but his model is still quite simple in that it assumes a static framework and only one source of nominal rigidity. He states that the construction of a true dynamic model "is likely to be an interesting line of future research". 
risk can have on the levels of consumption and leisure. These effects could be very important for welfare. Moreover, the usually employed linear approximation of the equations describing the equilibrium behavior of the model will represent a correct $t^{6}$ ranking of alternative policy regimes only under the very restrictive assumptions ${ }^{7}$ that are described by Woodford (2001). These restrictions will not be met in any reasonably rich general equilibrium model. Ideally, one would like to use a full second-order solution of the dynamic system. To date, the literature had been unable to consider these issues, because there was no model solution method that could handle them. What the literature has done to avoid this problem is to evaluate a world welfare function, basically transforming the two-country world into a closed economy. The papers by Benigno and Benigno (2000, 2003a, 2003b) abound in such examples. The reason for doing so is that in a closed economy linearization techniques could be accepted a bit easier although, again, some restrictive assumptions should be used. Of course, such an approach would prevent a serious consideration of any strategic issues, and, in particular, the investigation of the gains from international monetary cooperation. In other words, the Nash equilibrium just could not be found in a reasonably calibrated NOEM model. The recently developed second-order solution method for dynamic stochastic systems by Sims $(2003)^{8}$ overcomes this problem by making it possible to construct and evaluate correctly a country-specific welfare function.

It is true that technical diff culties are responsible for developing open-economy models that are either simple enough to be solved exactly or relatively too complex to render linearization methods helpful. Nevertheless, I would like to lay a stress again that the theoretical second generation literature of monetary cooperation has recently begun to realize that the rich microfoundations of the NOEM models provide fruitful grounds for introducing ineff ciencies that could generate nontrivial gains from cooperation.

At the same time contributions from the closed-economy literature (see Goodfriend and King (2000) and Woodford (2001)) that compellingly advance the case for price stability have strongly inf uenced the NOEM into working out models that advocate a zero-inf ation optimal policy in an open-economy framework. However, it is exactly the fact that the f exible-price allocation is the constrained Pareto-optimum in the cooperative solution which can also be arrived at from a decentralized point of view by simply eliminating price stickiness in individual countries $^{9}$, that has unfortunately prevented second-generation models from building more general models in which cooperation could be a natural policy. Benigno and Benigno [2003a, 2003b] and Pierpaolo Benigno (2001) are examples of theoretical contributions that recognize these issues.

\footnotetext{
6 Benigno and Benigno (2000, pp.39) argue that "The construction of an appropriate openeconomy microfounded country-specific welfare criterion is still an open issue".

7 For a detailed discussion of these assumptions see Section 4.

8 Second-order techniques are also developed by Schmitt-Grohe and Uribe (2001), and Sutherland (2002a).

9 For example, Corsetti and Pesenti (2001) and Devereux and Engel (2000) are models that demonstrate that with PCP and complete markets the fex-price allocation is a constrained Pareto-optimum from both centralized and decentralized perspectives. Corsetti and Pesenti's paper has been dubbed by Canzoneri and others "the workhorse model" of NOEM literature.
} 
The bottom line here is to realize that once we introduce some further frictions into the picture, the case for complete price or wage stability generally no longer applies. ${ }^{10}$ The optimal monetary policy for an individual country will require some degree of prices stickiness because, with multiple ineff ciencies, monetary authorities will actually be able to improve upon the f exible-price allocation by playing one ineff ciency against the other. In general, the Pareto optimum cannot be achieved. Then, from an international point of view, coordination of monetary policies might prove benef cial.

In view of the above, the reason that the model by Obstfeld and Rogoff (2002) generates very trivial gains from monetary cooperation arises from the fact that the authors assume a simple model with a small number of market imperfections. In this case the policymakers can address the imperfections and maximize welfare without any need for coordination. In other words, monetary authorities are able to achieve the same allocation under the centralized and decentralized solutions.

An alternative way to explain the lack of coordination benef ts and one that provides a very nice connection to the closed-economy optimal monetary policy literature is to look at the so-called "New Keynesian Phillips Curve." One common criticism of the Phillips Curve is that, if imperfect competition and sticky prices are the only two ineff ciencies, it does not imply any trade-off between inf ation and the output gap. Then, a policy of price stability will not only negate the effect of sticky prices, but will also close the output gap. If this is the case, in an open-economy framework, coordination of monetary policies will not be an issue, since domestic monetary policy can achieve a Pareto-optimum on its own.

The above consideration, however, will probably not hold in a model with multiple ineff ciencies since their presence will imply policy trade-offs that look different from the points of view of the individual countries and a benevolent central planner. It might be that foreign monetary authorities could help the domestic country achieve a greater welfare. Even though in a two-country world the "New Keynesian Phillips Curve" will always provide policy friction between inf ation and the output gap because of the presence of the terms of trade, it turns out that this effect does not matter with a Cobb-Douglas consumption index.

To generate potential gains from coordination, in addition to the standard features of incorporating monopolistically competitive producers who set prices in a staggered fashion as in Calvo (1983), this paper introduces new elements in the traditional NOEM model that could potentially give rise to gains from international monetary cooperation by creating policy trade-offs in the Nash equilibrium. First, it assumes staggered nominal wage contracts set by monopolistically competitive households. In this the study follows the closed-economy example by Erceg, Henderson and Levin (2000). Second, it has been suggested by Canzoneri, Cumby, and Diba (2002) that differential productivity disturbances in the traded and nontraded sectors can also bring about divergence in the Nash and cooperative equilibria. Third, in contrast to most contributions, the paper assumes that imports do not enter the domestic consumption bundle

10 For a fuller discussion see Obstfeld and Rogoff (2002) and Benigno and Benigno (2003a, 2003b). 
directly, but rather participate as an input to the domestic production process. While McCallum and Nelson (2001) introduce this assumption into an open-economy framework with a different goal in mind, it is Clarida, Gali, and Gertler (2002) who conjecture that this could potentially also lead to gains from cooperation. Fourth, the study assumes a combination of producer and local currency pricing in conjunction with the qualitative results of Corsetti and Pesenti (2001) who claim the presence of gains for intermediate levels of local currency pricing. Fifth, the paper checks Obstfeld and Rogoff's result that introducing a more general specif cation for real money balances in the utility function does not change the general f avor of their conclusions. Lastly, I assume a non-unitary elasticity of substitution between home and foreign goods as in Benigno (2002). However, it is worth noting that none of these assumptions has been shown quantitatively to generate gains from coordination in a realistically calibrated dynamic NOEM model.

The paper begins with a model that is close to the one employed by Obstfeld and Rogoff (2002) in that it requires the presence of sticky prices and monopolistic competition in the production sector only. Of course, even in this case the model will be richer in that it also includes multiperiod price stickiness. Then the ineff ciencies described in the previous section are added. This should allow us to determine which of accounts for the biggest gain in cooperation. Moreover, each of the proposed experiments will be conducted for global and country-specif c shocks. Obstfeld and Rogoff (2002) suggest that with global shocks there will not be any gains from cooperation. Also, robustness checks will be performed in order to evaluate the sensitivity of the results with respect to various calibrated parameter values. For example, in the Obstfeld and Rogoff's model there should be no gains from cooperation when the intertemporal elasticity of substitution is unitary.

The main f ndings can be summarized as follows. First, a non-unitary intratemporal elasticity of substitution gives rise to gains from coordination. Even though empirical studies estimate this elasticity to be different from one, ${ }^{11}$ the study f nds that it is not necessary for generating coordination benef ts. In particular, in the presence of local currency pricing and wage rigidities the gains from coordination are nontrivial even with a unitary elasticity of substitution between home and foreign goods. However, assuming differential productivity shocks across sectors of production, nonlogarithmic real money balances and imports used in the production process does not lead to cooperation gains with a Cobb-Douglas consumption index. At the same time, when the latter three factors are augmented with a constant elasticity of substitution consumption index, the gains are increased relative to the case with a Cobb-Douglas specif cation. For example, for a reasonable calibration of the parameters, the biggest gains realized are found to be around two percent of steady state consumption.

Another interesting result is that the assumption of global shocks does not lead to a coordination failure. As is emphasized in the original model of Obstfeld and Rogoff [2002], in the presence of multiple ineff ciencies, their basic result might not hold true even for global shocks. This outcome provides a bridge to older Keynesian models of coordination ${ }^{12}$ which analyzed

11 See, for example, Harrigan (1993) and Tref er and Lai (1999).

12 The principal conclusion of the Keynesian literature is that, in general, there will be gains from international 
predominantly global shocks.

This paper provides two main contributions. It is the frst study that quantif es the gains from cooperation generated in a dynamic NOEM model with a complex structure. The results show that it is possible to construct a NOEM model where international coordination of monetary policies matters in a signif cant way. Even more importantly, it underscores the fact that generating gains from cooperation might actually be quite easy. This casts a serious doubt on the claim by Obstfeld and Rogoff that individual countries should pursue self-oriented monetary rules. The policy implications are very clear. The welfare losses associated with such behavior might be quite important for countries not to consider the cooperation option. Notice that these conclusions come from a model with complete asset markets and this is exactly the framework that Obstfeld and Rogoff envision will render the gains from cooperation even smaller. ${ }^{13}$ Consistent with the logic of this paper when we assume incomplete asset market structure the gains from cooperation increase, although not dramatically, compared with a case with complete asset markets.

Second, the paper should be viewed as an attempt to ref ne the application of Woodford's (2001) methodology in an open economy. While in a closed economy a linearquadratic framework for the analysis of optimal monetary policy might be effective, its use in open economies is limited only to certain issues. In particular, its application to the investigation of strategic issues is not helpful. A quadratic-quadratic approach, where the quadratic approximation of the utility function is evaluated by a quadratic approximation of the equilibrium conditions, renders the former exercise and, for that matter, any similar exercise that involves strategic interactions between countries, possible.

It is also important to point out that I do not discuss the possibility that appropriately designed individual objective functions could potentially implement the coordination equilibrium in the Nash solution. A simple example is provided by Benigno and Benigno (2003b). However, even in this case they show that the conditions under which this is possible are quite restrictive and the constructed objective functions might not coincide with the actual welfare of the countries. Moreover, in a richer framework this may not be possible at all.

This paper is organized as follows. The next section introduces the model, Section 3 derives the welfare loss functions, Section 4 describes the game, Section 5 discusses the results, and Section 6 concludes.

\section{A general TWO-COUNTRY MODEL}

There are two countries in the world economy, "Home" and "Foreign". There are

monetary cooperation. While the details will depend on the nature of the shocks and the specif c models employed, the rationale for coordination was unambiguously advanced (see, for example, Hamada 1974,1976,1979; Johansen, 1980; Canzoneri and Gray, 1985; Oudiz and Sachs,1985; and Buiter and Marston,1985). The empirical support has, however, been much more modest (for a comprehensive survey see McKibbin,1997).

13 In their model, because of its simple structure, asset markets are redundant. 
complete asset markets. Home produces a continuum of differentiated traded and nontraded goods measured on the unit interval respectively by $l \in[0,1] l_{N} \in[0,1]$. The $f$ nal good is bundled together using the common assumption of an aggregator. The homogeneous imported good from abroad is index by $l_{I} \in[0,1]$. Monopolistically competitive importing f rms buy raw imports from abroad and turn them into reprocessed imported goods. There is also a continuum of monopolistically competitive $\mathrm{f}$ rms that produce the domestic differentiated goods. They use the reprocessed imported good and labor specif $\mathrm{c}$ to the production of traded goods. The $\mathrm{frms}$ producing nontraded goods are also monopolistically competitive but use only labor specif c to the production of nontraded goods. We also assume a continuum of monopolistically competitive households indexed on the unit interval by $h \in[0,1]$ that supply differentiated labor to the production sector.

\section{A. Consumption and Individual Preferences}

The representative consumer in the home country consumes traded and nontraded goods. The consumption index for the f nal consumption good is

$$
C_{t}=\frac{C_{T, t}^{\xi} C_{N, t}^{1-\xi}}{\xi^{\xi}(1-\xi)^{1-\xi}},
$$

where $(1-\xi)$ is the weight of nontraded goods in the f nal good. It is assumed that a fraction $s$ of f rms exhibit local currency pricing in that they set the price of goods in the currency of the buyer. The remaining fraction $(1-s)$ exhibit producer currency pricing in that they set the price of the goods in their own currency. Preferences over home and foreign tradable goods are then given by a CES index

$$
C_{T, t}=\left[(1-\gamma)^{\frac{1}{\mu}} C_{H, t}^{\frac{\mu-1}{\mu}}+\gamma s^{\frac{1}{\mu}} C_{F, t}^{L C P \frac{\mu-1}{\mu}}+(\gamma-\gamma s)^{\frac{1}{\mu}} C_{F, t}^{P C P \frac{\mu-1}{\mu}}\right]^{\frac{1}{1-\mu}}
$$

where $\mu>1$ is the elasticity of substitution between home and foreign goods, $\gamma$ determines the steady state share of imported goods in total consumption, $C_{H, t}, C_{F, t}^{L C P}, C_{F, t}^{P C P}$ represent respectively consumption of domestic goods, foreign LCP and PCP goods. Price indexes are def ned appropriately as the minimal nominal price to buy a unit of $\mathrm{f}$ nal or traded good

$$
\begin{aligned}
P_{t} & =P_{T, t}^{\xi} P_{N, t}^{1-\xi}, \\
P_{T, t} & =\left[(1-\gamma) P_{H, t}^{1-\mu}+\gamma s P_{F, t}^{1-\mu}+(\gamma-\gamma s)\left(e_{t} P_{F, t}^{*}\right)^{1-\mu}\right]^{\frac{1}{1-\mu}},
\end{aligned}
$$

where $P_{H, t}$ is the price index of home goods, $P_{F, t}$ is the price index of foreign goods priced directly in the home currency and $P_{F, t}^{*}$ is the price index of foreign goods priced in foreign currency. Static optimization implies the following demand functions 


$$
\begin{aligned}
C_{T, t} & =\xi\left(\frac{P_{T, t}}{P_{t}}\right)^{-1} C_{t}, \\
C_{N, t} & =(1-\xi)\left(\frac{P_{N, t}}{P_{t}}\right)^{-1} C_{t}, \\
C_{H, t} & =(1-\gamma)\left(\frac{P_{H, t}}{P_{T, t}}\right)^{-\mu} C_{T, t}, \\
C_{F, t} & =\gamma s\left(\frac{P_{F, t}}{P_{T, t}}\right)^{-\mu} C_{T, t}+(\gamma-\gamma s)\left(\frac{e_{t} P_{F, t}^{*}}{P_{T, t}}\right)^{-\mu} C_{T, t} .
\end{aligned}
$$

Analogous equations exist for the foreign country as well with the same elasticity of substitution $\mu$. The representative household $h$ in the home country maximizes the following utility function

$$
E_{t} \sum_{k=0}^{\infty} \beta^{k} \frac{C(h)_{t+k}^{1-\rho}}{1-\rho}+\frac{1}{1-\varepsilon}\left(\frac{M_{t+k}(h)}{P_{t+k}}\right)^{1-\varepsilon}-\frac{L_{H, t+k}(h)^{1+\psi_{H}}}{1+\psi_{H}}-\frac{L_{N, t+k}(h)^{1+\psi_{N}}}{1+\psi_{N}}
$$

where $E_{t}$ denoted the conditional expectations operator, $\beta$ is the inter-temporal discount factor that satisf es $0<\beta<1$ and $\psi_{H}$ and $\psi_{N}$ are the elasticities of labor supply for traded and nontraded labor. Although the utility function is inter- and intratemporally separable, it is fairly general $^{14}$. The budget constraint of the consumer is relatively standard and is given by

$$
\begin{aligned}
& P_{t} C_{t}(h)+M_{t}(h)+\sum_{n^{t+1}} V\left(n^{t+1} \mid n^{t}, h\right) B\left(n^{t+1}, h\right)-M_{t-1}(h)-\Pi_{t}(h) \\
= & W_{H, t}(h) L_{H, t}(h)+W_{N, t}(h) L_{N, t}(h)+B_{t}(h)+T_{t}(h) .
\end{aligned}
$$

We denote by $n^{t}=\left(n_{0}, \ldots, n_{t}\right)$ the history of events up through and including period. In period $t$, consumers in either country purchase state-contingent assets in the home currency, denoted by $B_{t+1}=B\left(n^{t+1}\right)$, which bear a return of exactly one unit of the home currency in period $t+1$ if state $n^{t+1}$ occurs. Consumers purchase these assets at the prices $V\left(n^{t+1} \mid n^{t}\right)$, which denotes the price of one unit of local currency at $n^{t+1}$ in units of home currency at state $n^{t}$. Households share the revenues from the frms in the traded, nontraded and importing sectors in equal proportion. Therefore, $\Pi_{t}(h)$ is def ned as

$$
\Pi_{t}(h)=\int_{0}^{1} \Pi_{H, t}(l) d l+\int_{0}^{1} \Pi_{N, t}\left(l_{N}\right) d l_{N}+\int_{0}^{1} \Pi_{F, t}\left(l_{I}\right) d l_{I} .
$$

The government balances its budget constraint each period and pays to each household a lump-sum transfer $T_{t}(h)$. The household maximizes (1) with respect to consumption, real money

14 Fuhrer (1997) argues that pure rational expectations forward-looking models with explicit microoptimization provide a bad match to real data. Of course, such models are not subject to the Lucas Critique. A possible solution is to incorporate ad-hoc backward-looking terms in the model which on its turn is quite unsatisfactory from a modelling point of view. Fuhrer (2000) offers another alternative which reconciles both modelling elegance and empirical match-he introduces time-nonseparabilty in the consumption component of the utility function. Bergin and Tchakarov (2003) consider such an extension in a two-country model. 
balances, labor specif $\mathrm{c}$ to the production of traded and nontraded goods, subject to (2) and its labor demand function which will be derived shortly. The f rst-order conditions are relatively well known and are not given for the sake of brevity.

\section{B. Firms and Price Setting}

\section{Domestic firms producing traded goods}

Domestic monopolistically competitive frms that are indexed on the unit interval produce differentiated traded goods which are bundled into a homogeneous home good by a constant returns to scale aggregator of the Dixit-Stiglitz (1977) form

$$
Y_{t}=\left[\int_{0}^{1} Y_{t}(l)^{\frac{\phi-1}{\phi}} d l\right]^{\frac{\phi}{\phi-1}}
$$

where $\phi>1$. The aggregator's demand for each good $Y_{H, t}(l)$ is given by

$$
Y_{t}(l)=\left(\frac{P_{H, t}(l)}{P_{H, t}}\right)^{-\phi} Y_{t}=\left(\frac{P_{H, t}(l)}{P_{H, t}}\right)^{-\phi}\left(Y_{H, t}+Y_{H, t}^{*}\right),
$$

where $Y_{H, t}$ and $Y_{H, t}^{*}$ denote the home and foreign demand for the domestically produced good. The differentiated good $Y_{t}(l)$ is produced by hiring labor specif $\mathrm{c}$ to the production of the traded good and buying processed imported good

$$
Y_{t}(l)=A_{H, t} I M_{F, t}^{\alpha}(l) L_{H, t}^{1-\alpha}(l) .
$$

Note that the productivity shock $A_{H, t}$ is the same for all domestic frms producing the traded good but, as will be seen shortly, is specif c to the traded goods sector. As suggested earlier, according to Canzoneri, Cumby, and Diba (2002), this is one possible channel for generating gains from cooperation. Another one is the assumption that imported goods are necessary for the production of domestic goods ${ }^{15}$. In Clarida, Gali and Gertler (2002) the gains from international monetary cooperation come about because marginal cost depends on foreign economic activity ${ }^{16}$. Here marginal cost, which is def ned as the minimal price for buying one unit of $Y_{t}(l)$, will be affected by foreign activity through the presence of imported goods

$$
M C_{H, t}=\frac{P_{F, t}^{\alpha} W_{H, t}^{1-\alpha}}{A_{H, t} \alpha^{\alpha}(1-\alpha)^{1-\alpha}} .
$$

Firms set prices in a staggered fashion a la Calvo (1983). In that a mass of $\left(1-\kappa_{H}\right)$ of f rms are allowed to change their prices. The rest of the f rms of mass $\kappa_{H}$ that do not change their prices

15 McCallum and Nelson (2001) argue that the inclusion of imported goods directly in the production process is important as this improves the dynamic properties of the model. This assumption is also used by Smets and Wouters (2002) in a small open economy model.

16 In particular, in the presence of "cost-push" shocks, if the intertemporal elasticity of substitution is different from 1, marginal cost depends on foreign output. 
enter the next period with the same price, i.e. $P_{H, t}\left(\kappa_{H}, l\right)=P_{H, t+1}\left(\kappa_{H}, l\right)$ and $P_{H, t}^{*}\left(\kappa_{H}, l\right)=$ $P_{H, t+1}^{*}\left(\kappa_{H}, l\right)^{17}$. Also $\kappa_{H}$ is time independent in that no matter how long a $\mathrm{fm}$ does not change its price it sill faces the same probability of doing so in each consecutive time period. The prof $t$ maximization problem for the $\mathrm{fms}$ that can reoptimize at time $t$ is

$$
\max _{P_{h, t}^{n e w}} E_{t} \sum_{k=0}^{\infty} \kappa_{H}^{k} \mu_{t, t+k} \Pi_{t+k}(l)
$$

where $\Pi_{t}(l)=\left(P_{H, t}^{n e w}-M C_{H, t}\right) Y_{H, t}(l)+\left(e_{t} P_{H, t}^{* \text { new }}-M C_{H, t}\right) Y_{H, t}^{*}(l)^{18}$ and $\mu_{t, t+k}$ is the pricing kernel that is assumed to equal the household's inter-temporal marginal rate of substitution in consumption. Notice that the producer currency pricing f rms f nd the optimal price $P_{H, t}^{n e w}$ for domestic consumers and charge foreign consumers $e_{t} P_{H, t}^{n e w}$. Local currency pricing f rms choose simultaneously $P_{H, t}^{\text {new }}$ and $P_{H, t}^{* \text { new }}$. The f rst-order conditions yield

$$
\begin{aligned}
P_{H, t}^{n e w} & =\frac{\phi}{\phi-1} \frac{E_{t} \sum_{k=0}^{\infty} \kappa_{H}^{k} \mu_{t, t+k} M C_{H, t+k} P_{H, t+k}^{-\phi} Y_{H, t+k}}{E_{t} \sum_{k=0}^{\infty} \kappa_{H}^{k} \mu_{t, t+k} P_{H, t+k}^{-\phi} Y_{H, t+k}} . \\
P_{H, t}^{* n e w} & =\frac{\phi}{\phi-1} \frac{E_{t} \sum_{k=0}^{\infty} \kappa_{H}^{k} \mu_{t, t+k} M C_{H, t+k} P_{H, t+k}^{*-\phi} Y_{H, t+k}^{*}}{E_{t} \sum_{k=0}^{\infty} \kappa_{H}^{k} \mu_{t, t+k} P_{H, t+k}^{*-\phi} Y_{H, t+k}^{*} e_{t+k}}
\end{aligned}
$$

As is usual with Calvo pricing, the optimal price is set so that discounted real marginal revenue is equal to discounted real marginal cost, all in expected value terms. The price indices for home traded goods can be written as

$$
\begin{aligned}
& P_{H, t}=\left[\sum_{\tau=0}^{\infty} \kappa_{H}\left(1-\kappa_{H}\right)^{\tau} P_{H, t-\tau}^{n e w^{1-\phi}}\right]^{\frac{1}{1-\phi}} \\
& P_{H, t}^{*}=\left[\sum_{\tau=0}^{\infty} \kappa_{H}\left(1-\kappa_{H}\right)^{\tau} P_{H, t-\tau}^{* n e w^{1-\phi}}\right]^{\frac{1}{1-\phi}}
\end{aligned}
$$

These can be rearranged to give the state equation for the domestic traded goods price index

$$
\begin{aligned}
& P_{H, t}=\left[\kappa_{H} P_{H, t-1}^{1-\phi}+\left(1-\kappa_{H}\right) P_{H, t}^{n e w^{1-\phi}}\right]^{\frac{1}{1-\phi}} \\
& P_{H, t}^{*}=\left[\kappa_{H} P_{H, t-1}^{* 1-\phi}+\left(1-\kappa_{H}\right) P_{H, t}^{* n e w^{1-\phi}}\right]^{\frac{1}{1-\phi}}
\end{aligned}
$$

17 The same assumption is adopted by Woodford (1996), Dotsey, King and Wolman (1999) and Benigno and Benigno (2003b) and Benigno (2001) among others. An alternative is to assume that prices are augmented by the unconditional gross rate of inf ation as in Erceg at.al (2000). Another approach is undertaken by Christiano, Eichenbaum and Evans (2001) who augment the prices by time-dependent inf ation.

18 Note that, as is discussed in Yun (1996), $P_{H, t}^{n e w}$ is not indexed and will be the same across f rms as they face the same demand functions and marginal costs. 


\section{Domestic firms producing nontraded goods}

The price decision of domestic frms in the nontraded goods sector is similar to the one of the f rms producing traded goods. The output aggregator is given by

$$
Y_{N, t}=\left[\int_{0}^{1} Y_{N, t}\left(l_{N}\right)^{\frac{\phi-1}{\phi}} d l_{N}\right]^{\frac{\phi}{\phi-1}}
$$

where $\phi>1$. The aggregator's demand for each good $Y_{N, t}\left(l_{N}\right)$ is given by

$$
Y_{N, t}(l)=\left(\frac{P_{N, t}\left(l_{N}\right)}{P_{N, t}}\right)^{-\phi} Y_{N, t} .
$$

The differentiated good $Y_{N, t}\left(l_{N}\right)$ is produced by a linear technology with a productivity parameter and labor specif $\mathrm{c}$ to the production of the nontraded goods

$$
Y_{N, t}\left(l_{N}\right)=A_{N, t} L_{N, t}\left(l_{N}\right) \text {. }
$$

Flexible prices are assumed. The price chosen by those f rms is then

$$
P_{N, t}=\frac{\phi}{\phi-1} M C_{N, t}
$$

where marginal cost is given by $M C_{N, t}=\frac{W_{N, t}}{A_{N, t}}$ and .

\section{Firms importing foreign goods}

Firms importing a homogeneous foreign good turn out differentiated import goods that are used both for consumption and production. The output aggregator is given by

$$
Y_{F, t}=\left[\int_{0}^{1} Y_{F, t}\left(l_{I}\right)^{\frac{\phi-1}{\phi}} d l_{I}\right]^{\frac{\phi}{\phi-1}} .
$$

For simplicity, we assume the same elasticity of substitution as in the traded and nontraded goods sectors. The overall demand for a processed imported good is given by

$$
Y_{F, t}\left(l_{I}\right)=\left(\frac{P_{F, t}\left(l_{I}\right)}{P_{F, t}}\right)^{-\phi} Y_{F, t}=\left(\frac{P_{F, t}\left(l_{I}\right)}{P_{F, t}}\right)^{-\phi}\left(C_{F, t}+I M_{F, t}\right)
$$

and the optimal $\mathrm{f}$ exible price is

$$
P_{F, t}=\frac{\phi}{\phi-1} M C_{F, t}
$$

Note that marginal cost is simply given by $M C_{F, t}=(1-s) e_{t} P_{F, t}^{*}+s P_{F, t}$. Also, we assume that importing goods are owned by domestic agents and therefore the pricing kernel is identical to the one used in the traded and nontraded goods sectors ${ }^{19}$. This concludes our discussion of the pricing 
decision undertaken in the home economy. Of course, similar equations exist for the foreign economy. It is clear that the structure in the production sectors is very rich. Analytical solutions are impossible in such a complex but arguably more realistic environment.

\section{Households and Wage Setting}

Following the work of Erceg and others (2000), I assume that households act as monopolistic competitors in that each one of them supplies differentiated labor service to the production sector. Households are indexed on the unit interval. The labor used by $\mathrm{fms}$ in the traded and nontraded goods sectors is def ned as a CES labor aggregator

$$
\begin{aligned}
L_{H, t} & =\left[\int_{0}^{1} L_{H, t}(h)^{\frac{\lambda-1}{\lambda}} d l\right]^{\frac{\lambda}{\lambda-1}}, \\
L_{N, t} & =\left[\int_{0}^{1} L_{N, t}(h)^{\frac{\lambda-1}{\lambda}} d l_{N}\right]^{\frac{\lambda}{\lambda-1}},
\end{aligned}
$$

where $\lambda>1$ is the elasticity of substitution between labor inputs. The price indexes def ned as the minimal nominal cost of producing one unit of the respective labor aggregate, taking wage rate as given, are

$$
\begin{aligned}
& W_{H, t}=\left[\int_{0}^{1} W_{H, t}(h)^{1-\lambda} d l\right]^{\frac{1}{\lambda-1}}, \\
& W_{N, t}=\left[\int_{0}^{1} W_{N, t}(h)^{1-\lambda} d l_{N}\right]^{\frac{1}{\lambda-1}} .
\end{aligned}
$$

The total demands for the labor services of household $h$ are

$$
\begin{aligned}
& L_{H, t}(h)=\left(\frac{W_{H, t}(h)}{W_{H, t}}\right)^{-\lambda} L_{H, t}, \\
& L_{N, t}(h)=\left(\frac{P_{N, t}(h)}{P_{N, t}}\right)^{-\lambda} L_{N, t} .
\end{aligned}
$$

Households set wages in staggered contracts in a similar fashion as in the production sector. A fraction $\left(1-\chi_{H}\right)$ of the agents that supply labor services in the traded goods sector may renegotiate their wages each period. Then, household chooses a wage rate $W_{H, t}^{n e w}(h)$ by maximizing (1) subject to the budget constraint (2) and taking as given the demand schedule for labor. The optimal wage is

$$
W_{H, t}^{n e w}=\frac{\lambda}{\lambda-1} \frac{E_{t} \sum_{k=0}^{\infty}\left(\chi_{H} \beta\right)^{k} L_{H, t}^{1+\psi_{H}}}{E_{t} \sum_{k=0}^{\infty}\left(\chi_{H} \beta\right)^{k} \frac{C_{t+k}^{-\rho}}{P_{t+k}} L_{H, t}} .
$$

appropriate pricing kernel to use is the foreign intertemporal marginal rate of substitution. However, since he employs a SOE model in which the rest of the world is taken for given, he uses as a pricing kernel in which payoffs are discounted with the world nominal interest rate. 
Again, as long as the household does not change the price of its wage contract, it enters the next period with the same wage. The new wage is set so that the discounted marginal utility of income is equalized to the discounted marginal disutility of working, both in expected value terms. Accordingly, the implied state equations for the aggregate wage rate

$$
W_{H, t}=\left[\chi_{H} W_{H, t-1}^{1-\lambda}+\left(1-\chi_{H}\right) W_{H, t}^{n e w^{1-\lambda}}\right]^{\frac{1}{1-\lambda}} .
$$

The wage rate in the nontraded is assumed to be f exible

$$
\frac{W_{N, t}}{P_{N, t}}=\frac{\lambda}{\lambda-1} \frac{L_{N, t}^{\psi_{N}}}{C_{t+k}^{-\rho}} .
$$

In the nontraded goods sector we get the familiar condition that the real wage is just a mark-up over the marginal rate of substitution of consumption for leisure. The assumption of sticky wages along with sticky prices is important since it incorporates a policy trade-off in the traditional open-economy Phillips curve. With $\mu=1$, without a trade-off between inf ation and output a policy that completely stabilizes the price level will automatically stabilize the output gap as well. This additional nominal rigidity may account for gains from international monetary cooperation as suggested by Benigno and Benigno (2003b) and Clarida and others (2002). The former show that time-varying degrees of monopolistic distortions may also account for cost-push shocks. The latter achieve the same results by bringing in exogenous variation in the market power they endow the households with. In any case neither of them presents quantitative estimations of the gains from cooperation.

\section{Market clearing conditions}

In the home and foreign countries market clearing implies

$$
\begin{gathered}
Y_{t}=Y_{H, t}+Y_{H, t}^{*}=C_{H, t}+C_{H, t}^{*}+I M_{t}^{*}, \\
Y_{t}^{*}=Y_{F, t}+Y_{F, t}^{*}=C_{F, t}+C_{F, t}^{*}+I M_{t}, \\
Y_{N, t}=C_{N, t} \\
Y_{N, t}^{*}=C_{N, t}^{*}
\end{gathered}
$$

where the starred variables denote foreign variables.

\section{The solution method}

The model is solved by the second-order accurate solution by Sims (2003). Here we present the basic relationships (for a detailed discussion see Sims).If we denote by $\eta$ the vector of all endogenous and exogenous variables, then the solution algorithm requires that the system is written in the following way

$$
\Psi\left(\eta_{t}, \eta_{t-1}, \varepsilon_{t}\right)+\Pi \varrho_{t}=c
$$

where $\varepsilon_{t}$ is the vector of shocks to the system and $\varrho_{t}$ is a function of the shocks when the model is solved. The only equations that have to be manipulated in order to satisfy the above timing 
$(t-1, t)$ requirement are the price and wage equations ${ }^{20}$ We expand the model to a second-order around a steady state given by

$$
\Psi(\bar{\eta}, \bar{\eta}, 0)
$$

The solution, then, can be written as

$$
\begin{aligned}
& y_{t}=F\left(y_{t-1}, \varepsilon_{t}\right), \\
& x_{t}=M\left(y_{t}\right),
\end{aligned}
$$

where $y_{t}$ and $x_{t}$ can be interpreted in the usual sense as the predetermined and forward-looking variables, respectively, and $\left[y_{t}^{\prime} x_{t}^{\prime}\right]=Z^{\prime} \eta_{t}$. The second-order expansion of the solution is

$$
\begin{aligned}
d y_{i t} & =F_{1 i j} d y_{j, t-1}+F_{2 i j} \varepsilon_{j t}+F_{3 i} \sigma^{2} \\
& +\frac{1}{2}\left(F_{11 i j k} d y_{j, t-1} d y_{k, t-1}+2 F_{12 i j k} d y_{j, t-1} \varepsilon_{k t}+F_{22 i j k} \varepsilon_{j t} \varepsilon_{k t}\right), \\
d x_{i t} & =M_{11 i j k} d y_{j t} d y_{k t}+M_{2 i} \sigma^{2},
\end{aligned}
$$

where the matrices $Z, F$ and $M$ are functions of the model parameters. Note as well that, in accordance with Sims [2003], we are using tensor notation, i.e. it is true that

$$
A_{i j k} B_{m n j q}=C_{i k m n q} \Leftrightarrow c_{i k m n q}=\sum_{j} a_{i j k} b_{m n j q} .
$$

We use (9) to compute the following unconditional frst and second moments of the system

$$
E\left[d \eta_{i} d \eta_{j}\right] \text { and } E\left[d \eta_{i}\right]
$$

In this computation we disregard those terms that are higher than second order.

\section{Monetary Policy}

The model is closed by choosing money supply rules for the home and foreign country. They are given by

$$
\begin{aligned}
M_{t} & =\bar{M} A_{H, t}^{\theta_{1}} A_{N, t}^{\theta_{2}} A_{F, t}^{* \theta_{3}} A_{N, t}^{* \theta_{4}} \\
M_{t}^{*} & =\bar{M}^{*} A_{H, t}^{\theta_{1}^{*}} A_{N, t}^{\theta_{2}^{*}} A_{F, t}^{* \theta_{3}^{*}} A_{N, t}^{* \theta_{4}^{*}}
\end{aligned}
$$

Monetary authorities respond actively to productivity disturbances to traded and nontraded goods production home and abroad. Note that policy rules of this kind will not represent a fully optimal monetary policy. In principle, the f rst-best optimal monetary policy will respond to all lagged and current state variables ${ }^{21}$. For our purposes, however, specifying monetary policy as in (11) and (12) is enough. Also, it is often argued that simple rules that are easily understood by the general public are highly desirable. I assume that monetary authorities can commit to those rules.

20 Appendix IV shows how this can be done.

21 See Weerapana (2000) for an example of a fully optimal monetary policy in a hybrid NOEM. 


\section{LosS FunCTION}

The loss function is derived using a second-order Taylor approximation to the utility function of the representative consumer and the techniques described by Woodford (2001). In that we assume that the monetary authorities maximize the unconditional expectations of the average of per period household utility functions, $\mathbf{W}_{t}$. As is customary we abstract from real monetary balances although we can easily incorporate them. Note that consumption will be the same across households within the separate country because of our assumption of complete asset markets in both countries.

$$
\mathbf{W}_{t}=\left(\frac{C_{t}^{1-\rho}}{1-\rho}-\int_{0}^{1} \frac{L_{H, t}(h)^{1+\psi_{H}}}{1+\psi_{H}} d h-\int_{0}^{1} \frac{L_{N, t}(h)^{1+\psi_{N}}}{1+\psi_{N}} d h\right)
$$

Appendix I derives the following second-order approximation

$$
\begin{aligned}
& \mathbf{W}_{t}-\overline{\mathbf{W}}=\bar{C}^{1-\rho} \widehat{C}_{t}-\frac{1}{2}(1-\rho) \bar{C}^{1-\rho} \widehat{C}_{t}^{2} \\
&-\bar{L}_{H}^{1+\psi_{H}} \widehat{L}_{H, t}-\frac{1}{2}\left(\psi_{H}+1\right) \bar{L}_{H}^{1+\psi_{H}} \widehat{L}_{H, t}^{2}-\frac{1}{2} \bar{L}_{H}^{1+\psi_{H}}\left(\frac{\lambda \psi_{H}+1}{\lambda}\right) \operatorname{var}_{h}\left[\widehat{L}_{H, t}(h)\right] \\
&-\bar{L}_{N}^{1+\psi_{N}} \widehat{L}_{N, t}-\frac{1}{2}\left(\psi_{N}+1\right) \bar{L}_{N}^{1+\psi_{N}} \widehat{L}_{N, t}^{2}-\frac{1}{2} \bar{L}_{N}^{1+\psi_{N}}\left(\frac{\lambda \psi_{N}+1}{\lambda}\right) \operatorname{var}_{h}\left[\widehat{L}_{N, t}(h)\right]+O\left(\|\xi\|^{3} .\right.
\end{aligned}
$$

where $\overline{\mathbf{W}}$ contains the constant terms from the approximation and $\operatorname{var}_{h}\left[\widehat{L}_{H, t}(h)\right]$ and $\operatorname{var}_{h}\left[\widehat{L}_{N, t}(h)\right]$ (Appendix II derives expressions for these two terms that are independent of $h$ ) denote the cross-sectional dispersion of labor effort among the households. When we pass the unconditional expectations operator through the terms on the right hand-side we could obtain an evaluation of the individual country loss function. While values for the second moments of the variables can be easily arrived at from a linear approximation to the system of equations, calculating the expected values of $\widehat{C}_{t}, \widehat{L}_{H, t}$ and $\widehat{L}_{N, t}$ is problematic. In our model the equilibrium will be affected by the variances of productivity shocks and, therefore, in general $\widehat{C}_{t}, \widehat{L}_{H, t}$ and $\widehat{L}_{N, t}$ will depend on the second moments of all other variables. This an idea that was f rst demonstrated by Obstfeld and Rogoff (1998).

In a closed economy Woodford (2001) overcomes this issue by introducing a subsidy to production activity so that the monopolistic distortions are eliminated. While this might seem somewhat artif cial, it has a deep mathematical justif cation. In general the fact that the analysis can be cast in a linear-quadratic framework seems quite appealing ${ }^{22}$.A log-linear approximation will be enough to deliver a correct computation of the quadratic loss function only if two conditions are met. First, the expansion should be around a steady state that is only negligibly different from the optimal one. But this is not enough. Not only do we have to expand about a nearly optimal steady state, but we also have to consider policies that deliver it. Thus, if we are primarily interested in optimal monetary policy, the second condition might be satisf ed. But

22 Woodford (2001) contends that this is very convenient since "we can address the nature of optimal policy within a linear-quadratic optimal control framework that has been extensively studied and, numerical computation of optimal policy is relatively easy." 
ensuring a f rst-best steady state requires a subsidy that completely removes the monopolistic distortion.

In an open-economy framework, satisfying these two conditions is a daunting task. Benigno and Benigno (2003a) demonstrate that monopolistic distortions should now be set at a positive value since the def ationary bias associated with the terms of trade coexists with the inf ationary bias associated with the presence of monopolistic distortions. Even this is done in a framework that is very restrictive in that it assumes either that the elasticity of substitution between home and foreign goods is unitary or that latter elasticity is equal to the reciprocal of the inter-temporal elasticity of substitution. Therefore, doing away with the frst-order terms in the loss function presents a signif cant challenge.

A second-order approximation of the equilibrium structural conditions in the sense of Sims (2003) saves the trouble of having to come up with ingenious methods for eliminating the frst-order terms in the welfare function. In this way, the expansion of the utility function can be done about a steady state that does not necessarily have to be arbitrarily close to the f rst-best.

Moreover, there is a much deeper reason for not wanting to take away the monopolistic distortion. It is true that there is a case for pursuing optimal policy both from a monetary and f scal point of view, that is, a monetary policy that tries to stabilize inf ation and a $\mathrm{f}$ scal policy that takes care of the monopolistic distortion. However, if we introduce a subsidy in order to get rid of it, we, effectively, kill off the link between monopolistic competition and sticky prices. But in the same time it is well known that the assumption of monopolistic power rationalizes the assumption of sticky prices. And only when we have sticky prices, can we f nd a room for monetary policy. Thus, if we eliminate the monopolistic distortion, then the active search of an appropriate monetary policy to eliminate the distortion associated with sticky prices becomes to a large extent meaningless. This argument resembles very much the one made by Obstfeld and Rogoff (1995), where they claim that the "marriage" of complete asset markets with rigid prices is unappealing, since, with complete asset markets it must be possible to devise contracts in such a way that the presence of sticky prices is completely internalized, i.e. contracts are indexed to any possible change in monetary policy. In any case, with multiple rigidities, even in a closed economy, the complete elimination of the monopolistic distortion would not guarantee that Woodford's conditions are met.

Even though for our purposes the write-up of loss function in (14) is enough, it is customary in the literature that uses Woodford's approach to further rearrange the welfare measure. We follow suit and derive the following unconditional expectation of the welfare measure (see Appendix III for derivation and def nition of the coeff cients)

$$
\begin{aligned}
E\left(\frac{\mathbf{W}_{t}-\overline{\mathbf{W}}}{\bar{C}^{1-\rho}}\right) & =E \widehat{C}_{t}-\varphi_{N}^{1} E\left(\widehat{Y}_{N, t}-\widehat{A}_{N, t}\right)-\varphi_{H}^{1} E\left(\widehat{Y}_{t}-\widehat{A}_{H, t}-\alpha \widehat{I M}_{t}\right) \\
+\frac{1}{2}(1-\rho) E \widehat{C}_{t}^{2}-\varphi_{N}^{2} E\left(\widehat{Y}_{N, t}-\widehat{A}_{N, t}\right)^{2} & -\varphi_{H}^{2} E\left(\widehat{Y}_{t}-\widehat{A}_{H, t}-\alpha \widehat{I M}_{t}\right)^{2} \\
& -\varphi_{H}^{3} E\left(\pi_{H}^{2}\right)-\varphi_{H}^{4} E\left[\omega_{H}^{2}\right]+O\left(\|\xi\|^{3} .\right.
\end{aligned}
$$


Equation (15) has a nice interpretation. The loss function increases with the increase in the variances of price and wage inf ation ${ }^{1}$, the variances of technology shocks, and the variance of consumption (provided $\rho>1$ ). Also, it depends on the frst moments of consumption, and the technology shocks. As we mentioned above the terms that are on the frst row are usually eliminated by a production subsidy.

\section{OPTIMAl COOPERATIVE AND NASH MONETARY POLICY}

The def nition of optimal monetary policy is very straightforward. In the cooperative case monetary authorities choose the parameters $\theta_{1}-\theta_{4}, \theta_{1}^{*}-\theta_{4}^{*}$ in the money supply rules (11) and (12) to maximize the joint welfare function

$$
E\left(\mathbf{V}_{t}\right)=\frac{1}{2} E\left(\mathbf{W}_{t}-\overline{\mathbf{W}}\right)+\frac{1}{2} E\left(\mathbf{W}_{t}^{*}-\overline{\mathbf{W}}^{*}\right)
$$

In the Nash case each policy maker chooses the parameters in its money rule to maximize its respective loss function taking the maximization problem of its counterpart abroad as given. The algorithm for solving this problem is also simple. For example, in the cooperative case, beginning with initial values for $\theta_{1}-\theta_{4}, \theta_{1}^{*}-\theta_{4}^{*}$, the model is solved and the $\mathrm{f}$ rst and second unconditional moments of the vector $\eta_{t}$ are computed using (9) and (10). Then an initial evaluation of the of the joint welfare function (16) is performed. A numerical search algorithm, then, is employed in order to $\mathrm{f}$ nd those parameters $\theta_{1}-\theta_{4}, \theta_{1}^{*}-\theta_{4}^{*}$ that maximize the joint welfare function. The solution in the Nash case is more complex and numerically intensive. For a given set of parameters in the foreign country $\theta_{1}^{*}-\theta_{4}^{*}$, the home country chooses $\theta_{1}-\theta_{4}$ such that they maximize $E\left(\mathbf{W}_{t}-\overline{\mathbf{W}}\right)$. Given these optimized values, the foreign country chooses $\theta_{1}^{*}-\theta_{4}^{*}$ such that $E\left(\mathbf{W}_{t}^{*}-\overline{\mathbf{W}}^{*}\right)$ is optimized. The process is performed until the parameters in the home and foreign countries converge.

\section{RESUlts}

The frst three rows in all the tables report the gains from coordination as percentage points of steady state consumption. The f rst row shows the gains from pursuing active Nash monetary policy relative to one in which monetary authorities choose a constant money supply rule, i.e. the response coeff cients in the money supply rules are set to zero. The second row presents the welfare benef ts from pursuing active coordinated policy relative to inactive monetary policy, and the third row shows the difference between the coordinated and Nash optimal policies. Row four is analogous to the one reported by Obstfeld and Rogoff (2002) and is just the ratio of rows three and one. It depicts the importance of coordination relative to stabilization gains. The last row is comparable to the one used in Sutherland (2002b) and shows the gains from coordination relative to the overall gains from active monetary policy.

1 Usually $E\left(\pi_{H}^{2}\right)$ is written as $\operatorname{var}\left(\pi_{H}^{2}\right)$ since $E\left(\pi_{H}\right)$ is of second-order and, thus, $E\left(\pi_{H}^{2}\right)=$ $\operatorname{var}\left(\pi_{H}^{2}\right)$ up to a second-order approximation. We prefer to keep, however, $E\left(\pi_{H}^{2}\right)$ and the other similar terms intact. 


\section{A. Calibration}

I assume that the relative weight of traded goods is $\xi=0.5$, the degree of monopolistic competition in the goods and wage sectors is $\lambda=\phi=7.66$ (See Rotemberg and Woodford,1998), the inverse of the elasticity of labor supply is $\psi=1$ ( See Christiano and others.,1997) and $\beta=0.99$. There is a wide range of estimates for the interest elasticity of real money balances $(1 / \epsilon)$ : from 0.39 in Chari and others (1998) to 0.05 in Mankiw and Summers (1986). Even though results are reported for different values of $\epsilon$ I call a reasonable calibration the one that chooses an intermediate value of $0.25(\epsilon=4)$. Empirical studies estimate the income elasticity of real money demand $(\rho / \epsilon)$ to be about unity, so in all experiments I set $\rho=\varepsilon$. Therefore, a reasonable calibration sets $\rho=4$. This happens to be in the range of the estimates for the coeff cient of relative risk aversion provided by Hall (1988) (as low as 1 and as high as 33) and also by Gali, Gertler and Lopez-Salido (2002) who suggest a value between 3 and 10.

The elasticity of substitution between home and foreign goods $\mu$ is a critical parameter in the experiments. According to some recent studies, such as Harrigan (1993) and Tref er and Lai (1999), a sensible assumption for this parameter is 6 . Results are shown for a range of values between 1 and 10. The parameters $\chi_{H}$ and $\kappa_{H}$ measure the degree of price stickiness. For the reasonable calibration experiment I choose $\chi_{H}=\kappa_{H}=0.75$ implying that prices are sticky for four periods. I follow the literature in assuming that the steady state value of imported goods in the traded goods consumption index is 0.5 . I do sensitivity analysis here as well for more reasonable values.

The calibration of the technology shocks is standard: the standard deviation is 0.01 and the persistence is 0.95 . These are values similar to those used in real business cycles studies such as Hansen (1985).

\section{B. Basic Case}

The basic case has only the two ineff ciencies that are usually assumed in the literatureimperfect competition and sticky prices. This case is similar to the one employed in Obstfeld and Rogoff (2002), but for the absence of traded goods. Table 1 reports the gains from cooperation for different values of the intratemporal elasticity of substitution $\mu$ and for logarithmic consumption, and real money balances. When $\mu=1$ there are no gains exactly as in the case of Obstfeld and Rogoff (2002). Domestic Nash monetary policy can achieve its objectives without the help of foreign authorities ${ }^{24}$. Increasing $\mu$ generates gains from coordination in accordance with the intuition and results of Benigno (2002) and Sutherland (2002b). For a reasonable calibration of the elasticity (setting it equal to 6 ), the gains can be as high as $0.26 \%$ of steady state consumption. The gain is signif cant not only as an absolute, but also as a relative magnitude. It represents about $15.5 \%$ of the overall gain. Note as well that $\mathrm{R}=0.18$ which is comparable to the biggest value reported by Obstfeld and Rogoff (2002) for $\rho=8$. It is also interesting to observe that for higher

24 Note that this will not be equivalent to the frst best, since we have not eliminated the distortions asscociated with monopolistic competititon. 
values of $\mu$ the Nash solution can be welfare inferior relative to the inactive monetary policy.

Table 2 checks the robustness of the result for different values of the coeff cient of relative risk aversion $\rho$ and the inverse of the interest elasticity of real money balances $\varepsilon$. In this experiment $\mu$ is one. Canzoneri and others (2002) argue that if $\varepsilon>1$, there will be more channels for international interdependence coming through the dependence of the exchange rate on the domestic and foreign price levels (with $\varepsilon=1$, the exchange rate will depend only on foreign and domestic money supplies). There are only negligible gains from coordination for higher values of $\rho$ and $\varepsilon$. This, however, conf rms the contention of Obstfeld and Rogoff (2002) that their basic results would go through for cases where real balances enter the utility function in a non-logarithmic way.

Table 3 presents results for more reasonable combinations of the parameters. When the intratemporal elasticity is equal to 6 , the gains from coordination increase with the increase of the inter-temporal elasticity. For example, for $\rho=4$ the gains are about $0.46 \%$ of steady state consumption and account for almost the whole possible gain from pursuing active monetary policy, i.e. about $92 \%$.

\section{Wage Case}

Relative to the basic case we introduce sticky wages along with sticky prices in the manner described in the presentation of the general model. The incorporation of another ineff ciency creates additional friction in the conduct of domestic monetary policy even with unitary elasticity of substitution between home and foreign goods. It is evident that Pareto optimality can not be arrived at even if monetary authorities choose to pursue a policy of constant prices, because this will not simultaneously close the output gap. Optimal monetary policy will choose some degree of price stickiness.

Table 4 illustrates this point. With $\mu=1$ and prices sticky for four periods there are no gains from cooperation if wages are f exible. However, if wages are sticky as well, there are non-trivial gains. For example, if wages are rigid for four periods, the benef ts are $0.35 \%$ of steady state consumption and represent as well about half of the overall gain from pursuing active stabilization policy. When the ineff ciency persists, i.e. wages become stickier, welfare gains also increase. Again, it is even possible that inactive monetary policy delivers higher welfare results than the Nash policy. It is conceivable that in such cases the frictions in the Nash game become so severe that countries are actually better-off when they do not respond to productivity disturbances. When we assume a CES consumption index with $\mu=6$, and prices and wages inf exible for four periods, the gains from coordination are raised substantially to about 1.23 percent of steady state consumption and also account for $235 \%$ of the overall gain from following active monetary policy.

It is worth pointing out that in the wage case we play 3 ineff ciencies one against another. Here monetary authorities face a very complex task. For a given $\mu>1$ they have to f nd the optimal level of both price and wage stickiness that delivers the least welfare loss. Also, the 
Wage case demonstrates that the assumption of Cobb-Douglas consumption index, which is very tractable to work with both theoretically and empirically, is not inconsistent with the presence of sizable gains from cooperation.

\section{Nontraded Goods Case}

Canzoneri and others(2002) provide a nice overview of what they call the "Workhorse model" for the study of macroeconomic interdependence. They recognize the fact "there must be a policy trade-off (or a friction) in the Nash solution if there is going to be a role for policy coordination". In a very simple static framework they show that the usual assumptions of unitary elasticity of substitution, balanced current account and a log specif cation for the utility of money give rise to a coordination failure. They conjecture that the incorporation of differential productivity shocks across traded and nontraded goods sectors will imply different trade-offs from an Nash and coordination point of view. In particular, they propose three scenarios. First, they assume that the shocks to the traded goods sectors are much more important that those to the nontraded goods sector and calculate $\mathrm{R}=1 / 15$. The second case reverses the importance of the shocks relative to the previous case and compute that $R=1 / 3$. In the last scenario they assume that the shocks to the export sector are much more important than the ones to the domestic and nontraded goods sector. Here they f nd that $\mathrm{R}=\infty$.

I consider only cases 1 and 2 from their analysis. Table 5 presents the results for the nontraded goods case. I assume originally that the standard deviations of the shocks to the traded and nontraded goods sectors are respectively 0.01 , and 0 . In other words this is scenario 1 in Canzoneri and others (2002). I f nd that there are small welfare gains of about 0.02 percent of steady state consumption and the ratio $\mathrm{R}=0.0586$ which is 3.5 times smaller than the one reported by Canzoneri and others(2002). The most interesting result, however, emerges from column 5 which reports the outcome of scenario 2 . The shocks to the nontraded goods sector are much more important that those to the traded goods sector in that the standard deviations to the former are 0.01 , whereas the standard deviations to the latter are 0 . In this case there are no gains whatsoever. In fact, the presence of nontraded shocks alone does not add additional frictions in the model for the "Workhorse" calibration of the model. This contrasts with the conclusion of Canzoneri and others (2002) and suggests that simple static models might not be very well equipped to capture signif cant dynamic features of the economy. Even though I do not consider their $\mathrm{f}$ nal scenario, in view of the above results, I would conjecture that it would also fail to deliver non-trivial results

In the same time, for reasonable calibration of the coeff cient of risk aversion, the inverse of the interest elasticity of money demand and the elasticity of substitution between home and foreign goods, it seems that the addition of nontraded goods shocks is important. For example, if $\rho=\varepsilon=4$ and $\mu=6$, the last column of Table 5 suggests that when shocks to nontraded goods are more important, the gains from cooperation could be as high as $1.11 \%$ of steady state consumption and also represent $206 \%$ of the overall welfare gain. Once again, it should be clear that it is not the presence of nontraded goods sector shocks that generates this result. Only when we have a non-unitary intratemporal elasticity, can the introduction of nontraded goods be essential for magnifying the gains from coordination. An empirical paper by Canzoneri, Cumby, 
and Diba (1999) fnds some evidence that it is really the case that the stochastic properties of the shocks to the traded and nontraded goods sectors are different.

\section{E. Import Case}

Clarida and others (2002) develop a two-country model and consider qualitatively the gains from international cooperation in monetary policy in the presence of cost-push shocks. In particular, in the presence of exogenous variation in the wage mark-up, they show that when the coeff cient of risk aversion is different from one, there are welfare benef ts from cooperation. It is useful to recognize that the cost-push shock generated by the exogenous variation in the wage mark-up is closely connected to the endogenously produced mark-up due to wage rigidity in Erceg and others (2000). In both cases they achieve the same goal-they create a policy trade-off between inf ation and output gap in the Phillips Curve.

In Clarida and others (2002) any value of $\rho>1$ leads to gains from cooperation. It is also the case that foreign output enters the marginal cost of the domestic country raised to power $(1-\rho)$, so that for a log specif cation of consumption in the utility function the gains disappear. This is the primary reason why Clarida and others (2002) consider the direct introduction of imported goods in the domestic production process a "particularly interesting" avenue for future research. I consider this possibility in the import case, which augments the basic case by assuming that a portion of the imported goods participate as an input in production. It is worth noting that it is McCallum and Nelson (2001) that introduce such an assumption in the NOEM literature for the f rst time. They claim that such a specif cation produces better dynamic performance of their model. In particular, this leads to an improved dynamic relationship between nominal exchange rate and inf ation and also is more successful at generating inf ation persistence. In the current model $\alpha$ denotes the steady state share of imported goods in production.

There is some empirical support for such an assumption. McCallum and Nelson (2001) argue that "productive inputs actually comprise a larger fraction of U.S. imports than do consumer goods". Smets and Wouters (2001) estimate an open-economy model calibrated to the euro area and $\mathrm{f}$ nd that the model has the best $\mathrm{ft}$ for $\gamma=0$ (recall that $\gamma$ represents the steady state value of imported goods in steady state consumption).

Table 6 reports the results in the import case. As was argued above the there are no gains from with $\mu=1$. This is shown in column 1 . The next column assumes that $\mu=6, \alpha=0.2$ and $\gamma=0.5$. The welfare gains are quite big, they reach $2.41 \%$ of steady state consumption and constitute about $81 \%$ of the overall gain from active monetary policy. Sensitivity analysis is provided for more reasonable values of $\alpha$ and $\gamma$. It is obvious that for a given $\alpha(\gamma)$ the gains decrease with the decrease of $\gamma(\alpha)$. It seems, however, that the importance of imported goods in the production process is bigger than that of imported goods in the consumption index. For example, for an empirically relevant value of steady state imported goods in domestic consumption of 0.2 and a steady state share of imported goods in production of 0.3 , that gains are $2.18 \%$ of steady state consumption and they represent close to half of the overall welfare benef ts. 
Once again, it should be kept in mind, as in the nontraded goods case, that the mere introduction of productive imported inputs in production is not an independent source of gains from cooperation. With more reasonable values of the intratemporal elasticity, however, the presence of imported goods as productive inputs can be signif cant.

\section{F. Local Currency Pricing Case}

Much recent work in open-economy macroeconomics has explored price stickiness in the local currency of the buyer (LCP) rather than the domestic currency of the producer (PCP) as assumed in rest of the exercises. As far as the issue of international coordination of monetary policy is concerned, Corsetti and Pesenti (2001) demonstrated that in the presence of some degree of LCP there will be gains from coordination even with a Cobb-Douglas specif cation of the consumption index. The authors show that for intermediate degrees of exchange rate pass-through closing the output gap completely will not be optimal and, therefore, in general, welfare benef ts will be realized from a coordination point of view. They argue that "whether these gains are sizable...remains an open issue left to further research".

I explore these issues in Table 7 for different degrees of LCP (recall that s denotes the fraction of $\mathrm{frms}$ that set their prices in the currency of the foreign consumer). When $\mu=1$, there are no gains from cooperation. This is in fact the familiar result of PCP. Increasing the degree of pass-through does lead to welfare benef ts. For example, when $s=0.4$ the gains are $0.11 \%$ of steady state consumption and also $16.7 \%$ of the overall gain. Raising further $s$ reduces the gains and with full LCP the gains are identical to those with PCP. The last column in the table reports the gains for a CES consumption index with $\mu=6$.

\section{G. Gains from Coordination with Global Shocks}

Table 8 shows results for global productivity shocks in the different cases considered above. The global shocks are introduced by assuming that the home and foreign productivity disturbances are perfectly correlated. In the basic case where only prices are rigid there are no gains in conjunction with the results by Obstfeld and Rogoff (2002). In the wage case there are small gains from coordination amounting to about $0.04 \%$ of steady state consumption. Notice, however, that the benef ts are signif cant as a relative magnitude as is demonstrated by the two ratios $\mathrm{R}$ and $\mathrm{V}$. The LCP case is the one with $s=0.4$. The gains are important as they reach 0.10 $\%$ of steady state consumption and are also close to $10 \%$ of the overall welfare gain. There are gains in the import case as well. However, as it was discussed above if $\mu=1$, the gains will no longer be present. The biggest gains are present in the the nontraded goods case. Here I assume that the shocks to traded and nontraded goods sectors are perfectly correlated across countries, but not across sectors. The gains can be very high reaching almost $0.55 \%$ of steady state consumption and $587 \%$ of the overall gain. If the shocks were perfectly correlated across sectors as well, there would be no gains from coordination.

In general, the presence of world shocks is not suff cient for the lack of coordination gains. This f nding is also consistent with the claim of Obstfeld and Rogoff [2002] from the 
beginning of the paper that in a more complex model their basic result might not hold even with global shocks.

\section{H. Gains from Coordination with Incomplete Asset Markets.}

In all experiments so far I have assumed complete asset markets. I relax this assumption because this rules out the type of beggar-thy-neighbor policies that lie at the heart of the externality arguments for coordination. Even though I already report non-trivial gains from cooperation, augmenting the model with incomplete asset markets will, most probably, lead to even more interesting results. Equation (2) is then re-written as:

$$
\begin{aligned}
P_{t} C_{t}(h)+ & M_{t}(h)-M_{t-1}(h)+B_{H, t}(h)-\left(1+i_{t-1}\right) B_{H, t-1}(h) \\
+A C_{H, t}-\Pi_{t}(h)-\left(1+i_{t-1}^{*}\right) e_{t} B_{F, t-1}(h)+e_{t} B_{F, t}(h) & -W_{H, t}(h) L_{H, t}(h) \\
& =W_{N, t}(h) L_{N, t}(h)+T_{t}(h),
\end{aligned}
$$

where the adjustment costs for buying foreign bonds is $A C_{H, t}=\frac{1}{2} \frac{\psi_{f}\left(\left(B_{F, t}+\overline{B_{F}}\right) / e_{t}\right)^{2}}{P_{F t}^{*} Y_{t}^{*}}$. Since equilibrium dynamics with incomplete asset markets possess a random walk component, a second-order solution would not be possible to obtain. Therefore, it is important to achieve stationarity and this is attained by the introduction of the adjustment costs that eliminate the unit root in the frst-order solution ${ }^{24}$. Home and foreign bonds are one-period risk-free securities which pay off gross nominal interest rates of $\left(1+i_{t-1}\right)$ and $\left(1+i_{t-1}^{*}\right)$.

The results are shown in table 9 for all the cases. While it is true that the gains from coordination are higher with incomplete asset markets, they are not signif cantly bigger. For example, in the basic case the gains from cooperation account now for almost all gains from pursuing active monetary policy, namely $98 \%$.

\section{Conclusion}

This paper examines quantitatively the gains from international coordination of monetary policy in a dynamic NOEM model. The most important result and contribution is the development of an NOEM model where cooperation is signif cant from a welfare point of view. The result, however, is much stronger. Not only is it shown that it is possible to construct a framework where the welfare losses from pursuing self-oriented monetary policy rules are large, but it is also demonstrated that it is quite easy to do so.

Gains from cooperation can directly arise when the standard "workhorse model" is augmented with different realistic features. While assuming a more empirically relevant calibration of the intratemporal elasticity of substitution is already one recognized avenue for

24 Scmitt-Grohe and Uribe (2002) present a quantitative comparison of different alternatives to negate the unit root in incomplete asset markets models. They consider fve specif cations: (1) a model with Uzawa-type preferences; (2) a model with a debt-elastic interest-rate premium; (3) a model with convex portfolio adjustment costs; (4) a model with complete asset markets;

(5) a model without stationarity-inducing features. All these specif cations arrive at similar model dynamics. 
generating welfare benef ts, it is not a necessary condition in itself. The incorporation of rigidity in real wages or local currency pricing can give rise to gains even with a Cobb-Douglas consumption index. In the presence of trade-offs in the Phillips curves, gains from coordination can be magnif ed if the model incorporates differential productivity shocks across sectors, or imported goods as inputs in the production process.

Another result is that with reasonable calibration of the basic parameters, gains can emerge even for global shocks. This provides a connection with the earlier Keynesian literature, which was primarily occupied with world shocks.

A second contribution is the extension of the Woodford methodology in an openeconomy framework. While analyzing optimal monetary policy in a linear-quadratic framework has been useful in a closed-economy setting, its application in open-economy models has been more problematic. The Sims (2003) solution method casts the analysis of optimal monetary policy in a quadratic-quadratic framework and allows for a much richer environment. This makes it possible to analyze important strategic issues in open-economy models, something that was not possible in past literature unless the model investigated was simple enough to be solved exactly.

This work suggests that individual countries should not care only about domestic stabilization policy. It is in fact desirable that the foreign stabilization problem is taken into account when formulating domestic monetary policies. Not considering it might imply signif cant welfare losses.

The model presented here can be extended in a variety of ways. Adding investment will def nitely add more realism to the model environment. With only technology shocks the model will not be able to match well the volatility of nominal variables and, in particular, the volatility of the nominal exchange rate, which could be important for optimal monetary policy. The introduction of money demand shocks can correct for that. 
Table 1. Gains from Cooperation in the Basic Case for Different Values of the Intra-temporal Elasticity of Substitution between Home and Foreign Goods (with logarithmic consumption and real money balances)

\begin{tabular}{ccccccc}
\hline \hline$\mu$ & 1 & 2 & 4 & 6 & 8 & 10 \\
\hline $\mathrm{W}^{\mathrm{N}}-\mathrm{W}^{\mathrm{I}}$ & $0.8112^{*}$ & 0.6487 & 0.4929 & 0.3296 & 0.1190 & -0.1364 \\
$\mathrm{~W}^{\mathrm{C}}-\mathrm{W}^{\mathrm{I}}$ & $0.8112^{* *}$ & 0.6570 & 0.5838 & 0.5899 & 0.6208 & 0.6637 \\
$\mathrm{~W}^{\mathrm{C}}-\mathrm{W}^{\mathrm{N}}$ & $0.0000^{* * *}$ & 0.0083 & 0.0909 & 0.2603 & 0.5018 & 0.8010 \\
\hline $\mathrm{R}=\frac{\mathrm{W}^{\mathrm{C}}-\mathrm{W}^{\mathrm{N}}}{\mathrm{W}^{\mathrm{N}}-\mathrm{W}^{\mathrm{T}}}$ & $0^{* * * *}$ & 0.0129 & 0.1844 & 0.7897 & 4.2168 & -5.8304 \\
$\mathrm{~V}=\frac{\mathrm{W}^{\mathrm{C}}-\mathrm{W}^{\mathrm{N}}}{\mathrm{W}^{\mathrm{C}}-\mathrm{W}^{\mathrm{T}}}$ & 0 & 0.0128 & 0.1557 & 0.4413 & 0.8083 & 1.2070 \\
\hline
\end{tabular}

${ }^{*}$ The numbers in the first row represent the welfare gains from pursuing

non-coordinated (Nash) but active policy relative to one in which monetary

authorities are inactive in that they are just following a constant money growth rule.

The gains are computed as \% of steady state consumption.

** The numbers in the first row represent the welfare gains from pursuing coordinated monetary policy

relative to one in which monetary authorities are inactive in that they are just following a constant money growth rule.

The gains are computed as \% of steady state consumption.

${ }^{* * *}$ The numbers in the first row represent the welfare gains from pursuing coordinated monetary policy

relative to one in which monetary authorities are playing the Nash game.

The gains are computed as \% of steady state consumption.

${ }^{* * * *}$ The ratios $\mathrm{R}$ and $\mathrm{V}$ show in two different ways the importance of pursuing a coordinated policy relative to a Nash policy. 
Table 2. Gains from Cooperation in the Basic Case for Different Values of the Coeff cient of Risk Aversion and the Inverse of the Interest Elasticity of Real Money Balances (with intra-temporal elasticity between home and foreign goods equal to 1)

\begin{tabular}{ccccc}
\hline \hline$\mu$ & 1 & 4 & 6 & 8 \\
\hline $\mathrm{W}^{\mathrm{N}}-\mathrm{W}^{\mathrm{I}}$ & $0.8112^{*}$ & 0.7817 & 0.7011 & 0.6312 \\
$\mathrm{~W}^{\mathrm{C}}-\mathrm{W}^{\mathrm{I}}$ & $0.8112^{* *}$ & 0.7880 & 0.7100 & 0.6436 \\
$\mathrm{~W}^{\mathrm{C}}-\mathrm{W}^{\mathrm{N}}$ & $0.0000^{* * *}$ & 0.0063 & 0.0089 & 0.0124 \\
\hline $\mathrm{R}=\frac{\mathrm{W}^{\mathrm{C}}-\mathrm{W}^{\mathrm{N}}}{\mathrm{W}^{\mathrm{N}}-\mathrm{W}^{\mathrm{T}}}$ & $0^{* * * *}$ & 0.0081 & 0.0125 & 0.0193 \\
$\mathrm{~V}=\frac{\mathrm{W}^{\mathrm{C}}-\mathrm{W}^{\mathrm{N}}}{\mathrm{W}^{\mathrm{C}}-\mathrm{W}^{\mathrm{T}}}$ & 0 & 0.0080 & 0.0127 & 0.0197 \\
\hline
\end{tabular}

${ }^{*}$ The numbers in the first row represent the welfare gains from pursuing

non-coordinated (Nash) but active policy relative to one in which monetary

authorities are inactive in that they are just following a constant money growth rule.

The gains are computed as \% of steady state consumption.

** The numbers in the first row represent the welfare gains from pursuing coordinated monetary policy

relative to one in which monetary authorities are inactive in that they are just following a constant money growth rule.

The gains are computed as \% of steady state consumption.

${ }^{* * *}$ The numbers in the first row represent the welfare gains from pursuing coordinated monetary policy

relative to one in which monetary authorities are playing the Nash game.

The gains are computed as \% of steady state consumption.

**** The ratios $\mathrm{R}$ and $\mathrm{V}$ show in two different ways the importance of pursuing a coordinated policy relative to a Nash policy. 
Table 3. Gains from Cooperation in the Basic Case for Different Values of the Coeff cient of Risk Aversion and the Inverse of the Interest Elasticity of Real Money Balances (with intra-temporal elasticity between home and foreign goods equal to 6)

\begin{tabular}{cccccc}
\hline \hline$\mu$ & 1 & 2 & 4 & 6 & 8 \\
\hline $\mathrm{W}^{\mathrm{N}}-\mathrm{W}^{\mathrm{I}}$ & $0.3296^{*}$ & 0.2592 & 0.0402 & -0.1296 & -0.3190 \\
$\mathrm{~W}^{\mathrm{C}}-\mathrm{W}^{\mathrm{I}}$ & $0.5899^{* *}$ & 0.6259 & 0.5032 & 0.7700 & 0.8488 \\
$\mathrm{~W}^{\mathrm{C}}-\mathrm{W}^{\mathrm{N}}$ & $0.2603^{* * *}$ & 0.3667 & 0.4630 & 0.8996 & 1.1678 \\
\hline $\mathrm{R}=\frac{\mathrm{W}^{\mathrm{C}}-\mathrm{W}^{\mathrm{N}}}{\mathrm{W}^{\mathrm{N}}-\mathrm{W}^{\mathrm{T}}}$ & $0.7897^{* * * *}$ & 1.4147 & 11.5174 & -6.9414 & -3.6608 \\
$\mathrm{~V}=\frac{\mathrm{W}^{\mathrm{C}}-\mathrm{W}^{\mathrm{N}}}{\mathrm{W}^{\mathrm{C}}-\mathrm{W}^{\mathrm{T}}}$ & 0.4413 & 0.5889 & 0.9201 & 1.1683 & 0.8083 \\
\hline
\end{tabular}

${ }^{*}$ The numbers in the first row represent the welfare gains from pursuing non-coordinated (Nash) but active policy relative to one in which monetary authorities are inactive in that they are just following a constant money growth rule.

The gains are computed as \% of steady state consumption.

${ }^{* *}$ The numbers in the first row represent the welfare gains from pursuing coordinated monetary policy relative to one in which monetary authorities are inactive in that they are just following a constant money growth rule. The gains are computed as \% of steady state consumption.

${ }^{* * *}$ The numbers in the first row represent the welfare gains from pursuing coordinated monetary policy relative to one in which monetary authorities are playing the Nash game.

The gains are computed as \% of steady state consumption.

${ }^{* * * *}$ The ratios $\mathrm{R}$ and $\mathrm{V}$ show in two different ways the importance of pursuing a coordinated policy relative to a Nash policy. 
Table 4. Gains from Cooperation in the Wage Case for Different Periods of Wage Stickiness (with coeff cient of risk aversion equal to 4 and prices sticky for 4 periods)

\begin{tabular}{ccccccc}
\hline \hline $\begin{array}{c}\text { Sticky wages } \\
\text { (periods) } \\
\mu\end{array}$ & 0 & 4 & 6 & 8 & 10 & 4 \\
\hline & 1 & 1 & 1 & 1 & 1 & 6 \\
\hline $\mathrm{W}^{\mathrm{N}}-\mathrm{W}^{\mathrm{I}}$ & $0.7818^{*}$ & 0.4919 & 0.1929 & -0.6006 & -0.8674 & -0.7106 \\
$\mathrm{~W}^{\mathrm{C}}-\mathrm{W}^{\mathrm{I}}$ & $0.7880^{* *}$ & 0.7990 & 0.6784 & 0.2273 & 0.1601 & 0.5245 \\
$\mathrm{~W}^{\mathrm{C}}-\mathrm{W}^{\mathrm{N}}$ & $0.0063^{* * *}$ & 0.3571 & 0.4655 & 0.8279 & 1.0275 & 1.2351 \\
\hline $\mathrm{R}=\frac{\mathrm{W}^{\mathrm{C}}-\mathrm{W}^{\mathrm{N}}}{\mathrm{W}^{\mathrm{N}}-\mathrm{W}^{\mathrm{I}}}$ & $0.0080^{* * * *}$ & 0.8081 & 2.4132 & -1.3785 & -1.1846 & -1.7381 \\
$\mathrm{~V}=\frac{\mathrm{W}^{\mathrm{C}}-\mathrm{W}^{\mathrm{N}}}{\mathrm{W}^{\mathrm{C}}-\mathrm{W}^{\mathrm{I}}}$ & 0.0081 & 0.4469 & 0.6862 & 3.6423 & 6.4179 & 2.3548 \\
\hline
\end{tabular}

${ }^{*}$ The numbers in the first row represent the welfare gains from pursuing non-coordinated (Nash) but active policy relative to one in which monetary authorities are inactive in that they are just following a constant money growth rule.

The gains are computed as \% of steady state consumption.

${ }^{* *}$ The numbers in the first row represent the welfare gains from pursuing coordinated monetary policy relative to one in which monetary authorities are inactive in that they are just following a constant money growth rule.

The gains are computed as \% of steady state consumption.

*** The numbers in the first row represent the welfare gains from pursuing coordinated monetary policy relative to one in which monetary authorities are playing the Nash game. The gains are computed as \% of steady state consumption.

**** The ratios $\mathrm{R}$ and $\mathrm{V}$ show in two different ways the importance of pursuing a coordinated policy relative to a Nash policy. 
Table 5. Gains from Cooperation in the Non-traded Goods Case for Different Standard Deviations of the Traded and Non-traded Goods Shocks

\begin{tabular}{ccccccc}
\hline \hline sd (tr. goods shock) & 0.01 & 0.01 & 0.01 & 0.01 & 0.00 & 0.00 \\
sd (nontr. goods shock) & 0.00 & 0.00 & 0.01 & 0.01 & 0.01 & 0.01 \\
$\rho, \varepsilon$ & 1 & 4 & 1 & 4 & 1 & 4 \\
$\mu$ & 1 & 6 & 1 & 6 & 1 & 6 \\
\hline & & & & & & \\
$\mathrm{W}^{\mathrm{N}}-\mathrm{W}^{\mathrm{I}}$ & $0.3429^{*}$ & -0.1037 & 0.3429 & -0.7553 & 0.0000 & -0.8590 \\
$\mathrm{~W}^{\mathrm{C}}-\mathrm{W}^{\mathrm{I}}$ & $0.3630^{* *}$ & 0.1580 & 0.3630 & 0.0960 & 0.000 & 0.2540 \\
$\mathrm{~W}^{\mathrm{C}}-\mathrm{W}^{\mathrm{N}}$ & $0.0201^{* * *}$ & 0.2617 & 0.0201 & 0.8513 & 0.0000 & 1.1130 \\
& & & & & & \\
\hline $\mathrm{R}=\frac{\mathrm{W}^{\mathrm{C}}-\mathrm{W}^{\mathrm{N}}}{\mathrm{W}^{\mathrm{N}}-\mathrm{W}^{\mathrm{T}}}$ & $0.0586^{* * * *}$ & -2.2536 & 0.0586 & -1.1271 & n.a. & -1.2956 \\
$\mathrm{~V}=\frac{\mathrm{W}^{\mathrm{C}}-\mathrm{W}^{\mathrm{N}}}{\mathrm{W}^{\mathrm{C}}-\mathrm{W}^{\mathrm{T}}}$ & & & & & & \\
\hline
\end{tabular}

${ }^{*}$ The numbers in the first row represent the welfare gains from pursuing

non-coordinated (Nash) but active policy relative to one in which monetary authorities are inactive in that they are just following a constant money growth rule.

The gains are computed as \% of steady state consumption.

${ }^{* *}$ The numbers in the first row represent the welfare gains from pursuing coordinated monetary policy relative to one in which monetary authorities are inactive in that they are just following a constant money growth rule. The gains are computed as $\%$ of steady state consumption.

${ }^{* * *}$ The numbers in the first row represent the welfare gains from pursuing coordinated monetary policy relative to one in which monetary authorities are playing the Nash game.

The gains are computed as \% of steady state consumption.

${ }^{* * * *}$ The ratios $\mathrm{R}$ and $\mathrm{V}$ show in two different ways the importance of pursuing a coordinated policy relative to a Nash policy. 
Table 6. Gains from Cooperation in the Import Case for Different Steady State Shares of Processed Goods in the Consumption Index and Ouput Process (with coeff cient of risk aversion and inverse of the interest elasticity of real money balances equal to 4)

\begin{tabular}{ccccccc}
\hline \hline$\gamma$ & 0.5 & 0.5 & 0.3 & 0.2 & 0.2 & 0.2 \\
$\alpha$ & 0.2 & 0.2 & 0.2 & 0.3 & 0.2 & 0.1 \\
$\mu$ & 1 & 6 & 6 & 6 & 6 & 6 \\
\hline & & & & & & \\
$\mathrm{W}^{\mathrm{N}}-\mathrm{W}^{\mathrm{I}}$ & $2.6523^{*}$ & 0.5588 & 1.0799 & 2.8218 & 1.1527 & 0.6864 \\
$\mathrm{~W}^{\mathrm{C}}-\mathrm{W}^{\mathrm{I}}$ & $2.6635^{* *}$ & 2.9765 & 2.9755 & 5.0111 & 2.2643 & 1.4208 \\
$\mathrm{~W}^{\mathrm{C}}-\mathrm{W}^{\mathrm{N}}$ & $0.0112^{* * *}$ & 2.4177 & 1.8956 & 2.1893 & 1.1126 & 0.7344 \\
\hline $\mathrm{R}=\frac{\mathrm{W}^{\mathrm{C}}-\mathrm{W}^{\mathrm{N}}}{\mathrm{W}^{\mathrm{N}}-\mathrm{W}^{\mathrm{I}}}$ & $0.0042^{* * * *}$ & 4.3266 & 1.7553 & 0.7759 & 0.9652 & 1.0699 \\
$\mathrm{~V}=\frac{\mathrm{W}^{\mathrm{C}}-\mathrm{W}^{\mathrm{N}}}{\mathrm{W}^{\mathrm{C}}-\mathrm{W}^{\mathrm{I}}}$ & 0.0042 & 0.8123 & 0.6371 & 0.4369 & 0.4914 & 2.0611 \\
\hline
\end{tabular}

${ }^{*}$ The numbers in the first row represent the welfare gains from pursuing

non-coordinated (Nash) but active policy relative to one in which monetary authorities are inactive in that they are just following a constant money growth rule.

The gains are computed as $\%$ of steady state consumption.

${ }^{* *}$ The numbers in the first row represent the welfare gains from pursuing coordinated monetary policy relative to one in which monetary authorities are inactive in that they are just following a constant money growth rule. The gains are computed as \% of steady state consumption.

${ }^{* * *}$ The numbers in the first row represent the welfare gains from pursuing coordinated monetary policy relative to one in which monetary authorities are playing the Nash game.

The gains are computed as \% of steady state consumption.

${ }^{* * * *}$ The ratios $\mathrm{R}$ and $\mathrm{V}$ show in two different ways the importance of pursuing a coordinated policy relative to a Nash policy. 
Table 7. Gains from Cooperation in the local currency pricing Case for Different Values of Exchange Rate Pass-Through (with coeff cient of risk aversion and inverse of the interest elasticity of real money balances equal to 4 , and unitary elasticity between home and foreign goods)

\begin{tabular}{cccccccc}
\hline \hline$s$ & 0 & 0.2 & 0.4 & 0.6 & 0.8 & 1 & 0.4 \\
$\mu$ & 1 & 1 & 1 & 1 & 1 & 1 & 6 \\
\hline & & & & & & & \\
$\mathrm{W}^{\mathrm{N}}-\mathrm{W}^{\mathrm{I}}$ & $0.7817^{*}$ & 0.6716 & 0.5810 & 0.7274 & 0.7664 & 0.8490 & 0.8988 \\
$\mathrm{~W}^{\mathrm{C}}-\mathrm{W}^{\mathrm{I}}$ & $0.7880^{* *}$ & 0.7366 & 0.6981 & 0.7589 & 0.7780 & 0.8517 & 1.1800 \\
$\mathrm{~W}^{\mathrm{C}}-\mathrm{W}^{\mathrm{N}}$ & $0.0063^{* * *}$ & 0.0650 & 0.1171 & 0.0315 & 0.0118 & 0.0027 & 0.2812 \\
\hline $\mathrm{R}=\frac{\mathrm{W}^{\mathrm{C}}-\mathrm{W}^{\mathrm{N}}}{\mathrm{W}^{\mathrm{N}}-\mathrm{W}^{\mathrm{T}}}$ & $0.0081^{* * * *}$ & 0.0968 & 0.2015 & 0.0433 & 0.0154 & 0.0032 & 0.3129 \\
$\mathrm{~V}=\frac{\mathrm{W}^{\mathrm{C}}-\mathrm{W}^{\mathrm{N}}}{\mathrm{W}^{\mathrm{C}}-\mathrm{W}^{\mathrm{T}}}$ & 0.0080 & 0.0882 & 0.1677 & 0.0415 & 0.0152 & 0.0032 & 0.2383 \\
\hline
\end{tabular}

${ }^{*}$ The numbers in the first row represent the welfare gains from pursuing

non-coordinated (Nash) but active policy relative to one in which monetary authorities are inactive in that they are just following a constant money growth rule.

The gains are computed as \% of steady state consumption.

${ }^{* *}$ The numbers in the first row represent the welfare gains from pursuing coordinated monetary policy relative to one in which monetary authorities are inactive in that they are just following a constant money growth rule. The gains are computed as $\%$ of steady state consumption.

*** The numbers in the first row represent the welfare gains from pursuing coordinated monetary policy relative to one in which monetary authorities are playing the Nash game.

The gains are computed as \% of steady state consumption.

${ }^{* * * *}$ The ratios $\mathrm{R}$ and $\mathrm{V}$ show in two different ways the importance of pursuing a coordinated policy relative to a Nash policy. 
Table 8. Gains from Cooperation with Global Shocks

\begin{tabular}{cccccc}
\hline \hline Case & Price & Wage & Trade & Import & LCP \\
$\rho, \varepsilon$ & 4 & 4 & 4 & 4 & 4 \\
$\mu$ & 6 & 6 & 6 & 6 & 6 \\
\hline & & & & & \\
$\mathrm{W}^{\mathrm{N}}-\mathrm{W}^{\mathrm{I}}$ & $0.1285^{*}$ & 0.0674 & -0.4584 & 1.1294 & 0.9878 \\
$\mathrm{~W}^{\mathrm{C}}-\mathrm{W}^{\mathrm{I}}$ & $0.1285^{* *}$ & 0.1088 & 0.0941 & 1.2932 & 1.0898 \\
$\mathrm{~W}^{\mathrm{C}}-\mathrm{W}^{\mathrm{N}}$ & $0.0000^{* * *}$ & 0.0414 & 0.5525 & 0.1638 & 0.1020 \\
& & & & & \\
\hline $\mathrm{R}=\frac{\mathrm{W}^{\mathrm{C}}-\mathrm{W}^{\mathrm{N}}}{\mathrm{W}^{\mathrm{N}}-\mathrm{W}^{\mathrm{T}}}$ & $0.0000^{* * * *}$ & 0.6142 & -1.2063 & 0.1450 & 0.1032 \\
$\mathrm{~V}=\frac{\mathrm{W}^{\mathrm{C}}-\mathrm{W}^{\mathrm{N}}}{\mathrm{W}^{\mathrm{C}}-\mathrm{W}^{\mathrm{I}}}$ & 0.0000 & 0.3855 & 5.8714 & 0.1267 & 0.0935 \\
\hline
\end{tabular}

${ }^{*}$ The numbers in the first row represent the welfare gains from pursuing

non-coordinated (Nash) but active policy relative to one in which monetary authorities are inactive in that they are just following a constant money growth rule.

The gains are computed as \% of steady state consumption.

${ }^{* *}$ The numbers in the first row represent the welfare gains from pursuing coordinated monetary policy relative to one in which monetary authorities are inactive in that they are just following a constant money growth rule. The gains are computed as \% of steady state consumption.

${ }^{* * *}$ The numbers in the first row represent the welfare gains from pursuing coordinated monetary policy relative to one in which monetary authorities are playing the Nash game.

The gains are computed as \% of steady state consumption.

${ }^{* * * *}$ The ratios $\mathrm{R}$ and $\mathrm{V}$ show in two different ways the importance of pursuing a coordinated policy relative to a Nash policy. 
Table 9. Gains from Cooperation with Incomplete Asset Markets

\begin{tabular}{cccccc}
\hline \hline Case & Price & Wage & Trade & Import & LCP \\
$\rho, \varepsilon$ & 4 & 4 & 4 & 4 & 4 \\
$\mu$ & 6 & 6 & 6 & 6 & 6 \\
\hline & & & & & \\
$\mathrm{W}^{\mathrm{N}}-\mathrm{W}^{\mathrm{I}}$ & $0.0145^{*}$ & -0.1134 & -0.9866 & 0.5294 & 0.9124 \\
$\mathrm{~W}^{\mathrm{C}}-\mathrm{W}^{\mathrm{I}}$ & $1.2283^{* *}$ & 0.5961 & 0.1161 & 3.1932 & 1.4258 \\
$\mathrm{~W}^{\mathrm{C}}-\mathrm{W}^{\mathrm{N}}$ & $1.2138^{* * *}$ & 1.7095 & 1.1027 & 2.6638 & 0.5134 \\
\hline $\mathrm{R}=\frac{\mathrm{W}^{\mathrm{C}}-\mathrm{W}^{\mathrm{N}}}{\mathrm{W}^{\mathrm{N}}-\mathrm{W}^{\mathrm{T}}}$ & $83.7101^{* * * *}$ & -15.0749 & -1.1176 & 5.0317 & 0.5626 \\
$\mathrm{~V}=\frac{\mathrm{W}^{\mathrm{C}}-\mathrm{W}^{\mathrm{N}}}{\mathrm{W}^{\mathrm{C}}-\mathrm{W}^{\mathrm{I}}}$ & 0.9881 & 2.8678 & 9.4978 & 0.8324 & 0.3600 \\
\hline
\end{tabular}

${ }^{*}$ The numbers in the first row represent the welfare gains from pursuing

relative to one in which monetary authorities non-coordinated (Nash) but active policy

are inactive in that they are just following a constant money growth rule.

The gains are computed as \% of steady state consumption.

${ }^{* *}$ The numbers in the first row represent the welfare gains from pursuing coordinated monetary policy

relative to one in which monetary authorities are inactive in that they are just following a constant money growth rule.

The gains are computed as \% of steady state consumption.

${ }^{* * *}$ The numbers in the first row represent the welfare gains from pursuing coordinated monetary policy

relative to one in which monetary authorities are playing the Nash game.

The gains are computed as \% of steady state consumption.

${ }^{* * * *}$ The ratios $\mathrm{R}$ and $\mathrm{V}$ show in two different ways the importance of pursuing a coordinated policy relative

to a Nash policy. 
We begin with the consumption part of the utility function. A second-order Taylor expansion yields

$$
\frac{C_{t}^{1-\rho}}{1-\rho}=\frac{\bar{C}^{1-\rho}}{1-\rho}+\bar{C}^{1-\rho} \widehat{C}_{t}-\frac{1}{2} \rho \bar{C}^{1-\rho} \widehat{C}^{2}+O\left(\|\xi\|^{3}\right)
$$

where a hat denoted $\log$ deviation from the steady state and $O\left(\|\xi\|^{3}\right)$ collects all terms that are higher than second order. Expanding further $C_{t} / \bar{C}=1+\widehat{C}_{t}+\frac{1}{2} \widehat{C}^{2}$ and substituting into (A.1) gives

$$
\frac{C_{t}^{1-\rho}}{1-\rho}=\frac{\bar{C}^{1-\rho}}{1-\rho}+\bar{C}^{1-\rho} \widehat{C}_{t}-\frac{1}{2}(1-\rho) \bar{C}^{1-\rho} \widehat{C}^{2}+O\left(\|\xi\|^{3} .\right.
$$

Now we proceed with a second-order approximation of the labor services supplies to the traded sector

$$
\frac{L_{H, t}(h)^{1+\psi_{H}}}{1+\psi_{H}}=\frac{\bar{L}_{H}^{1+\psi_{H}}}{1+\psi_{H}}+\bar{L}_{H}^{1+\psi_{H}} \widehat{L}_{H, t}(h)+\frac{1}{2} \psi_{H} \bar{L}_{H}^{1+\psi_{H}} \widehat{L}_{H, t}^{2}(h)+O\left(\|\xi\|^{3} .\right.
$$

Note that from here onwards we drop the constant terms. They are all summarized in the constant $\Phi$ Using that $L_{H, t} / \bar{L}=1+\widehat{L}_{H, t}+\frac{1}{2} \widehat{L}_{H, t}^{2}$ and substituting in (A.3) delivers the following result

$$
\frac{L_{H, t}(h)^{1+\psi_{H}}}{1+\psi_{H}}=\frac{\bar{L}_{H}^{1+\psi_{H}}}{1+\psi_{H}}+\bar{L}_{H}^{1+\psi_{H}} \widehat{L}_{H, t}(h)+\frac{1}{2}\left(\psi_{H}+1\right) \bar{L}_{H}^{1+\psi_{H}} \widehat{L}_{H, t}^{2}(h)+O\left(\|\xi\|^{3} .\right.
$$

Integrating the last expression over $\mathrm{h}$ gives

$$
\begin{aligned}
\int_{0}^{1} \frac{L_{H, t}(h)^{1+\psi_{H}}}{1+\psi_{H}} d h= & \frac{\bar{L}_{H}^{1+\psi_{H}}}{1+\psi_{H}}+\bar{L}_{H}^{1+\psi_{H}} E_{h}\left[\widehat{L}_{H, t}(h)\right] \\
& +\frac{1}{2}\left(\psi_{H}+1\right) \bar{L}_{H}^{1+\psi_{H}} E_{h}\left[\widehat{L}_{H, t}^{2}(h)\right]+O\left(\|\xi\|^{3}\right.
\end{aligned}
$$

Employing a second-order Taylor approximation of the aggregator for labor used in the production of traded goods (3)

$$
\widehat{L}_{H, t}=E_{h}\left[\widehat{L}_{H, t}(h)\right]+\frac{1}{2} \frac{\lambda-1}{\lambda} \operatorname{var}_{h}\left[\widehat{L}_{H, t}(h)\right]+O\left(\|\xi\|^{3}\right.
$$

Using the def nition of $\operatorname{var}_{h}\left[\widehat{L}_{H, t}(h)\right]$, and substituting in (A.5), we obtain

$$
\begin{aligned}
\int_{0}^{1} \frac{L_{H, t}(h)^{1+\psi_{H}}}{1+\psi_{H}} d h=\bar{L}_{H}^{1+\psi_{H}}\left[\widehat{L}_{H, t}-\frac{1}{2} \frac{\lambda-1}{\lambda} \operatorname{var}_{h}\left[\widehat{L}_{H, t}(h)\right]\right. \\
+\frac{1}{2}\left(\psi_{H}+1\right) \bar{L}_{H}^{1+\psi_{H}}\left[E_{h}\left(\widehat{L}_{H, t}(h)\right)^{2}+\operatorname{var}_{h}\left(\widehat{L}_{H, t}(h)\right]+O\left(\|\xi\|^{3} .\right.\right.
\end{aligned}
$$

Once again making use of (A.6) and abstracting from terms that are higher that second-order simplif es (A.7)

$$
\begin{aligned}
\int_{0}^{1} \frac{L_{H, t}(h)^{1+\psi_{H}}}{1+\psi_{H}} d h=\bar{L}_{H}^{1+\psi_{H}} \widehat{L}_{H, t} & +\frac{1}{2}\left(\psi_{H}+1\right) \bar{L}_{H}^{1+\psi_{H}} \widehat{L}_{H, t}^{2} \\
+ & \frac{1}{2} \bar{L}_{H}^{1+\psi_{H}}\left(\left(\psi_{H}+1\right)-\frac{\lambda-1}{\lambda}\right) \operatorname{var}_{h}\left[\widehat{L}_{H, t}(h)\right]+O\left(\|\xi\|^{3} .\right.
\end{aligned}
$$


We obtain a similar expression about labor used in the nontraded sector

$$
\begin{aligned}
\int_{0}^{1} \frac{L_{N, t}(h)^{1+\psi_{N}}}{1+\psi_{N}} d h=\bar{L}_{N}^{1+\psi_{N}} \widehat{L}_{N, t} & +\frac{1}{2}\left(\psi_{N}+1\right) \bar{L}_{N}^{1+\psi_{N}} \widehat{L}_{N, t}^{2} \\
+ & \frac{1}{2} \bar{L}_{N}^{1+\psi_{N}}\left(\left(\psi_{N}+1\right)-\frac{\lambda-1}{\lambda}\right) \operatorname{var}_{h}\left[\widehat{L}_{N, t}(h)\right]+O\left(\|\xi\|^{3} .\right.
\end{aligned}
$$

The combination of (A.2), (A.8) and (A.9) gives equation (14) in the text. 
From equation (4) in the main text we obtain

$$
\log L_{H, t}(h)=\log L_{H, t}-\lambda\left[\log W_{H, t}(h)-\log W_{H, t}\right] .
$$

Taking variances of both sides yields

$$
\operatorname{var}_{h}\left(\log L_{H, t}(h)\right)=\lambda^{2} \operatorname{var}_{h}\left(\log W_{H, t}(h)\right) .
$$

With Calvo pricing it is possible to show that (see for example Woodford [2001])

$$
\operatorname{var}_{h}\left(\log W_{H, t}(h)\right)=\psi_{H} \operatorname{var}_{h}\left(\log W_{H, t-1}(h)\right)+\frac{\psi_{H}}{1-\psi_{H}}\left(\log \frac{\widehat{W}_{H, t}}{\widehat{W}_{H, t-1}}\right)^{2}
$$

A second-order approximation of $\left(\log \frac{W_{H, t}}{W_{H, t-1}}\right)^{2}$ can be written as

$$
\left(\log \frac{W_{H, t}}{W_{H, t-1}}\right)^{2}=\widehat{W}_{H, t}^{2}+\widehat{W}_{H, t-1}^{2}-2 \widehat{W}_{H, t} \widehat{W}_{H, t-1}+O\left(\|\xi\|^{3}\right.
$$

Substituting (B.3) into (B.2) gives

$$
\operatorname{var}_{h}\left(\log W_{H, t}(h)\right)=\psi_{H} \operatorname{var}_{h}\left(\log W_{H, t-1}(h)\right)+\widehat{W}_{H, t}^{2}+\widehat{W}_{H, t-1}^{2}-2 \widehat{W}_{H, t} \widehat{W}_{H, t-1}
$$

Now taking unconditional expectations of (B.4) and substituting the result in (B.1) derives an expression for $\operatorname{var}_{h}\left(\log L_{H, t}(h)\right.$

$$
E\left[\operatorname{var}_{h}\left(\log L_{H, t}(h)\right]=\lambda^{2} \frac{\psi_{H}}{\left(1-\psi_{H}\right)^{2}} E\left[\widehat{W}_{H, t}^{2}+\widehat{W}_{H, t-1}^{2}-2 \widehat{W}_{H, t} \widehat{W}_{H, t-1}\right]+O\left(\|\xi\|^{3} .\right.\right.
$$

Similarly, we have

$$
E\left[\operatorname{var}_{l}\left(\log Y_{H, t}(l)\right]=\phi^{2} \frac{\kappa_{H}}{\left(1-\kappa_{H}\right)^{2}} E\left[\widehat{P}_{H, t}^{2}+\widehat{P}_{H, t-1}^{2}-2 \widehat{P}_{H, t} \widehat{P}_{H, t-1}\right]+O\left(\|\xi\|^{3}\right.\right.
$$

Since the prices and wages in the nontraded and import sector are f exible, we will just have $E\left[\operatorname{var}_{l}\left(\log Y_{N, t}(l)\right]=0\right.$, $E\left[\operatorname{var}_{h}\left(\log L_{N, t}(h)\right]=0\right.$

and $E\left[\operatorname{var}_{l}\left(\log I M_{t}(l)\right]=0\right.$ 
A second-order Taylor approximation to the aggregate demand for nontraded labor $L_{N, t}=\int_{0}^{1} L_{N, t}\left(l_{N}\right) d l_{N}$ is

$$
\widehat{L}_{N, t}=E_{l_{N}}\left[\widehat{L}_{N, t}\left(l_{N}\right)\right]+\frac{1}{2} \operatorname{var}_{l_{N}}\left[\widehat{L}_{N, t}\left(l_{N}\right)\right]+O\left(\|\xi\|^{3} .\right.
$$

But from the production technology we have $\widehat{Y}_{N, t}\left(l_{N}\right)=\widehat{A}_{N, t}+\widehat{L}_{N, t}\left(l_{N}\right)$. Then it follows that $E_{l_{N}}\left[\widehat{Y}_{N, t}\left(l_{N}\right)\right]=\widehat{A}_{N, t}+E_{l_{N}}\left[\widehat{L}_{N, t}\left(l_{N}\right)\right]$ and

$\operatorname{var}_{l_{N}}\left[\widehat{Y}_{N, t}\left(l_{N}\right)\right]=\operatorname{var}_{l_{N}}\left[\widehat{L}_{N, t}\left(l_{N}\right)\right]$. Substituting the last two expressions in (C.1) gives

$$
\widehat{L}_{N, t}=E_{l_{N}}\left[\widehat{Y}_{N, t}\left(l_{N}\right)\right]-\widehat{A}_{N, t}+\frac{1}{2} \operatorname{var}_{l_{N}}\left[\widehat{Y}_{N, t}\left(l_{N}\right)\right]+O\left(\|\xi\|^{3} .\right.
$$

A second-order Taylor approximation to the aggregate supply for nontraded labor is similar to (A.6)

$$
\widehat{L}_{N, t}=E_{h}\left[\widehat{L}_{N, t}(h)\right]+\frac{1}{2} \frac{\lambda-1}{\lambda} \operatorname{var}_{h}\left[\widehat{L}_{N, t}(h)\right]+O\left(\|\xi\|^{3}\right.
$$

Therefore, using (C.2) we get

$$
\begin{aligned}
E_{h}\left[\widehat{L}_{N, t}(h)\right]=E_{l_{N}}\left[\widehat{Y}_{N, t}\left(l_{N}\right)\right]-\widehat{A}_{N, t}+\quad & \frac{1}{2} \operatorname{var}_{l_{N}}\left[\widehat{Y}_{N, t}\left(l_{N}\right)\right] \\
& -\frac{1}{2} \frac{\lambda-1}{\lambda} \operatorname{var}_{h}\left[\widehat{L}_{N, t}(h)\right]+O\left(\|\xi\|^{3} .\right.
\end{aligned}
$$

But since $\left.E_{l}\left[\widehat{Y}_{N, t}(l)\right]=\widehat{Y}_{N, t}-\frac{1}{2} \frac{\phi-1}{\phi} \operatorname{var}_{l_{N}}\left[\widehat{Y}_{N, t}\left(l_{N}\right)\right]\right]+O\left(\|\xi\|^{3}\right.$,then

$$
E_{h}\left[\widehat{L}_{N, t}(h)\right]=\widehat{Y}_{N, t}-\widehat{A}_{N, t}+\frac{1}{2 \phi} \operatorname{var}_{l_{N}}\left[\widehat{Y}_{N, t}\left(l_{N}\right)\right]-\frac{1}{2} \frac{\lambda-1}{\lambda} \operatorname{var}_{h}\left[\widehat{L}_{N, t}(h)\right]+O\left(\|\xi\|^{3} .\right.
$$

Substitute (C.4) into (A.5), omitting the terms that are constant and those higher that second order , and using the def nition of $\operatorname{var}_{h}\left[\widehat{L}_{H, t}(h)\right]$ to get

$$
\begin{aligned}
\int_{0}^{1} \frac{L_{N, t}(h)^{1+\psi_{N}}}{1+\psi_{N}} d h=\bar{L}_{N}^{1+\psi_{N}} & \left(\widehat{Y}_{N, t}-\widehat{A}_{N, t}+\frac{1}{2 \phi} \operatorname{var}_{l_{N}}\left[\widehat{Y}_{N, t}\left(l_{N}\right)\right]\right)+ \\
& \frac{1}{2}\left(\psi_{H}+1\right) \bar{L}_{N}^{1+\psi_{N}}\left(\widehat{Y}_{N, t}-\widehat{A}_{N, t}\right)^{2}+ \\
& \frac{1}{2} \bar{L}_{N}^{1+\psi_{N}}\left(\left(\psi_{H}+1\right)-\frac{\lambda-1}{\lambda}\right) \operatorname{var}_{h}\left[\widehat{L}_{N, t}(h)\right]+O\left(\|\xi\|^{3} .\right.
\end{aligned}
$$

Taking unconditional expectation of (C.5) and making use of (B.5) and (B.6) yields

$$
E \int_{0}^{1} \frac{L_{N, t}(h)^{1+\psi_{N}}}{1+\psi_{N}} d h=\frac{1}{\bar{C}^{1-\rho}}\left(\varphi_{N}^{1} E\left(\widehat{Y}_{N, t}-\widehat{A}_{N, t}\right)+\varphi_{N}^{2} E\left(\widehat{Y}_{N, t}-\widehat{A}_{N, t}\right)^{2}\right)+O\left(\|\xi\|^{3}\right.
$$

where $\varphi_{N}^{1}=\bar{L}_{N}^{1+\psi_{N}}=\frac{\lambda-1}{\lambda} \frac{\bar{W}_{N} \bar{L}_{N}}{\overline{P C}}, \varphi_{N}^{2}=\frac{1}{2}\left(\psi_{N}+1\right) \frac{\lambda-1}{\lambda} \frac{\bar{W}_{N} \bar{L}_{N}}{\overline{P C}}$. The same sequence of equations can be used to derive 
the unconditional expectation of disutility of working in the traded goods sector. The demand side gives us the following

$$
\begin{aligned}
\widehat{L}_{H, t}=\frac{1}{1-\alpha}\left(E_{l}\left[\widehat{Y}_{t}(l)\right]-\widehat{A}_{H, t}\right. & \left.\left.-\alpha E_{l} \widehat{\left[\widehat{I M}_{t}\right.}(l)\right]\right) \\
& \left.+\frac{1}{2(1-\alpha)^{2}}\left(\operatorname{var}_{l}\left[\widehat{Y}_{t}(l)\right]+\alpha^{2} \operatorname{var}_{l} \widehat{[I M}_{t}(l)\right]\right)+O\left(\|\xi\|^{3}\right.
\end{aligned}
$$

Note that here we have disregarded the term $\operatorname{cov}_{l}\left(\widehat{I M}_{t}(l), \widehat{Y}_{t}(l)\right)$. From the supply side we have $\widehat{L}_{H, t}=E_{h}\left[\widehat{L}_{H, t}(h)\right]+\frac{1}{2} \frac{\lambda-1}{\lambda} \operatorname{var}_{h}\left[\widehat{L}_{H, t}(h)\right]+O\left(\|\xi\|^{3}\right.$. The last expression combined with (C.7) is

$$
\begin{aligned}
& \left.E_{h}\left[\widehat{L}_{H, t}(h)\right]=\frac{1}{1-\alpha}\left(E_{l}\left[\widehat{Y}_{t}(l)\right]-\widehat{A}_{H, t}-\alpha E_{l} \widehat{I M_{t}}(l)\right]\right) \\
& \left.\quad+\frac{1}{2(1-\alpha)^{2}}\left(\operatorname{var}_{l}\left[\widehat{Y}_{t}(l)\right]+\alpha^{2} \operatorname{var}_{l} \widehat{\left[M_{t}\right.}(l)\right]\right)-\frac{1}{2} \frac{\lambda-1}{\lambda} \operatorname{var}_{h}\left[\widehat{L}_{H, t}(h)\right]+O\left(\|\xi\|^{3} .\right.
\end{aligned}
$$

Since $E_{l}\left[\widehat{Y}_{t}(l)\right]=\widehat{Y}_{H, t}-\frac{1}{2} \frac{\phi-1}{\phi} \operatorname{var}_{l}\left[\widehat{Y}_{t}(l)\right]+O\left(\|\xi\|^{3}\right.$ and $E_{l}\left[\widehat{I M}_{t}(l)\right]=\widehat{I M}_{t}-\frac{1}{2} \frac{\phi-1}{\phi} \operatorname{var}_{l}\left[\widehat{I M}_{t}(l)\right]+O\left(\|\xi\|^{3},(\mathrm{C} .8)\right.$ can be rearranged as

$$
\begin{aligned}
E_{h}\left[\widehat{L}_{H, t}(h)\right]=\frac{1}{1-\alpha}\left(\widehat{Y}_{t}-\widehat{A}_{H, t}-\alpha \widehat{I M}_{t}\right)+ & \frac{1+\alpha \phi-\alpha}{2 \phi(1-\alpha)^{2}} \operatorname{var}_{l}\left[\widehat{Y}_{t}(l)\right] \\
& +\frac{\alpha(\phi-1+\alpha)}{2 \phi(1-\alpha)^{2}} \operatorname{var}_{l}\left[\widehat{I M}_{t}(l)\right]-\frac{1}{2} \frac{\lambda-1}{\lambda} \operatorname{var}_{h}\left[\widehat{L}_{H, t}(h)+O\left(\|\xi\|^{3}\right.\right.
\end{aligned}
$$

Using (C.9) we get an analogous expression to (C.5)

$$
\begin{aligned}
& \int_{0}^{1} \frac{L_{H, t}(h)^{1+\psi_{H}}}{1+\psi_{H}} d h= \\
& \bar{L}_{H}^{1+\psi_{H}}\left(\frac{1}{1-\alpha}\left(\widehat{Y}_{H, t}-\widehat{A}_{H, t}-\alpha \widehat{I M}_{t}\right)+\frac{1+\alpha \phi-\alpha}{2 \phi(1-\alpha)^{2}} \operatorname{var}_{l}\left[\widehat{Y}_{t}(l)\right]+\frac{\alpha(\phi-1+\alpha)}{2 \phi(1-\alpha)^{2}} \operatorname{var}_{l}\left[\widehat{I M}_{t}(l)\right]\right) \\
&+\frac{1}{2}\left(\psi_{H}+1\right) \bar{L}_{H}^{1+\psi_{H}}\left(\frac{1}{1-\alpha}\left(\widehat{Y}_{t}-\widehat{A}_{H, t}-\alpha \widehat{I M}_{t}\right)\right)^{2} \\
& \quad+\frac{1}{2} \bar{L}_{H}^{1+\psi_{H}}\left(\left(\psi_{H}+1\right)-\frac{\lambda-1}{\lambda}\right) \operatorname{var}_{h}\left[\widehat{L}_{H, t}(h)\right]+O\left(\|\xi\|^{3} .\right.
\end{aligned}
$$

Taking unconditional expectations of (C.10) together with (B.5) and (B.6) gives

$$
\begin{aligned}
E \int_{0}^{1} \frac{L_{H, t}(h)^{1+\psi_{H}}}{1+\psi_{H}} d h & =\frac{1}{\bar{C}^{1-\rho}}\left(\varphi_{H}^{1} E\left(\widehat{Y}_{t}-\widehat{A}_{H, t}-\widehat{\alpha I M_{t}}\right)+\right. \\
& \left.\varphi_{H}^{2} E\left(\widehat{Y}_{t}-\widehat{A}_{H, t}-\widehat{\alpha I M_{t}}\right)^{2}+\varphi_{H}^{3} E\left(\pi_{H}^{2}\right)+\varphi_{H}^{4} E\left[\omega_{H}^{2}\right]\right)+O\left(\|\xi\|^{3} .\right.
\end{aligned}
$$

where $\varphi_{H}^{1}=\bar{L}_{H}^{1+\psi_{H}} \frac{1}{1-\alpha}=\frac{1}{1-\alpha} \frac{\lambda-1}{\lambda} \frac{\bar{W}_{H} \bar{L}_{H}}{\overline{P C}}, \varphi_{H}^{3}=\frac{1}{2}\left(\psi_{H}+1\right) \frac{\lambda-1}{\lambda} \frac{\bar{W}_{H} \bar{L}_{H}}{\overline{P C}} \frac{1}{(1-\alpha)^{2}}$,

$\varphi_{H}^{2}=\frac{\lambda-1}{\lambda} \frac{\bar{W}_{H} \bar{L}_{H}}{\overline{P C}} \frac{\phi(1+\alpha \phi-\alpha)}{(1-\alpha)^{2}} \frac{\kappa_{H}}{\left(1-\kappa_{H}\right)^{2}}, \varphi_{H}^{4}=\frac{\lambda-1}{\lambda} \frac{\bar{W}_{H} \bar{L}_{H}}{\overline{P C}}\left(\psi_{H}+1\right) \frac{\psi_{H}}{\left(1-\psi_{H}\right)^{2}}$. 
In this appendix I show how to cast the Calvo pricing equations in timing $(t-1, t)$. Take for example the optimal price equation for domestic f nal-good producers which I reproduce here for convenience

$$
P_{H, t}^{* n e w}=\frac{\phi}{\phi-1} \frac{E_{t} \sum_{k=0}^{\infty} \kappa_{H}^{k} \mu_{t, t+k} M C_{H, t+k} P_{H, t+k}^{*-\phi} Y_{H, t+k}^{*}}{E_{t} \sum_{k=0}^{\infty} \kappa_{H}^{k} \mu_{t, t+k} P_{H, t+k}^{*-\phi} Y_{H, t+k}^{*} e_{t+k}}
$$

Let us introduce two new state variables $F_{t}$ and $G_{t}$ that are def ned as

$$
\begin{gathered}
F_{t}=E_{t} \sum_{k=0}^{\infty} \kappa_{H}^{k} \mu_{t, t+k} M C_{H, t+k} P_{H, t}^{-\phi} Y_{H, t} \\
G_{t}=E_{t} \sum_{k=0}^{\infty} \kappa_{H}^{k} \mu_{t, t+k} P_{H, t}^{-\phi} Y_{H, t}
\end{gathered}
$$

Updating (D.2) and (D.3) by one period and taking expectations at time $t$ allows us to def ne the following recursive relationships

$$
\begin{aligned}
& F_{t}=f_{t}+\beta \kappa_{H} E_{t}\left(F_{t+1}\right), \\
& G_{t}=g_{t}+\beta \kappa_{H} E_{t}\left(G_{t+1}\right),
\end{aligned}
$$

where $f_{t}=M C_{H, t} Y_{H, t} P_{H, t}^{-\phi} /\left(P_{t} C_{t}^{\rho}\right)$ and $g_{t}=P_{H, t}^{-\phi} Y_{H, t} /\left(P_{t} C_{t}^{\rho}\right)$. Then, (D.1) can f nally be written as

$$
P_{H, t}^{n e w}=\frac{\phi}{\phi-1} \frac{F_{t}}{G_{t}}
$$

Similar relationships hold for the other prices $P_{N, t}^{n e w}, P_{F, t}^{n e w}, W_{H, t}^{n e w}, W_{N, t}^{n e w}$. 


\section{References}

Benigno, Gianluca, and Pierpaolo Benigno, 2000, "Monetary Policy Rules and the Exchange Rate,” (unpublished; Berkeley: UC Berkeley; New Jersey: Princeton University).

— , 2003a, "Price Stability in Open Economies," Review of Economic Studies, Vol. 70(4) No. 245, pp. 743-764.

_ 2003b, "Designing Targeting Rules for International Monetary Cooperation," (unpublished; London: Bank of England; New York: New York University).

Benigno, Pierpaolo, 2001, "Price Stability with Imperfect Financial Integration," (unpublished; New York, New York: New York University).

— , 2002, "A Simple Approach to International Monetary Policy Coordination," Journal of International Economics, Vol. 57, No. 1, pp. 177-96.

Bergin, Paul, and Ivan Tchakarov, 2003, "Does Exchange Rate Risk Matter for Welfare? A Guantitative Investigation,” NBER Working Paper No. 9900 (Cambridge, Massachusetts: National Bureau of Economic Research).

Bryant, Ralph, 1993, Evaluating Policy Regimes: New Research in Empirical Macroeconomics (Washington, DC: The Brookings Institution Press).

Buiter, M., and Richard Marston, 1985, ed., "International Economic Policy Coordination" (Cambridge: Cambridge University Press).

Calvo, G., 1983, “Staggered Price Setting in a Utility-maximising Framework," Journal of Monetary Economics, Vol. 12, pp. 983-98.

Canzoneri, Matthew, and JoAnna Gray, 1985, "Monetary Policy Games and the Consequences of Noncooperative Behavior," International Economic Review, Vol. 26, No. 3, pp. 547-64.

_ Economies" (Cambridge: MIT Press).

Canzoneri, Matthew, Robert Cumby, and Behzad Diba, 1999, "Relative Labor Productivity and the Real Exchange Rate in the Long Run: Evidence for a Panel of OECD Countries," Journal of International Economics, Vol. 47, pp. 246-65.

_ 2002, "The Need for International Policy Coordination: What's Old, What's New, What's Yet to Come?" (unpublished; Washington, DC: Georgetown University). 
Chari, V.V., Patrick Kehoe, and Ellen McGrattan, 1998, "Can Sticky Price Models Generate Volatile and Persistent Real Exchange Rates?" Staff Report No. 223, (December) (Minneapolis: Federal Reserve Bank of Minneapolis).

Christiano, Lawrence J., M. Eichenbaum, and C. Evans, 1997, "Sticky Price and Limited Participation Models of Money: A Comparison," European Economic Review, Vol. 41, pp. 1201-249.

Christiano, Lawrence J., M. Eichenbaum, and C. Evans, 2001, "Nominal Rigidities and the Dynamic Effects of a Shock to Monetary Policy," NBER Working Paper No. 8403 (Cambridge, Massachusetts: National Bureau of Economic Research).

Clarida, Richard, Jordi Gali, and Mark Gertler, 2002, “A Simple Framework for International Monetary Policy Analysis, Journal of Monetary Economics, Vol. 49, pp.879-904.

Cole, H., and M. Obstfeld, 1991, "Commodity Trade and International Risk Sharing: How Much do Financial Markets Matter?” Journal of Monetary Economics, Vol. 28.

Corsetti, Giancarlo, and Paolo Pesenti, 2001, "International Dimensions of Optimal Monetary Policy,” NBER Working Paper No. 8230 (Cambridge, Massachusetts: National Bureau of Economic Research).

Cooper, Richard, 1968, The Economics of Interdependence (New York: McGraw-Hill), pp. 157-58.

Devereux, M., and Charles Engel, 2000, "Monetary Policy in Open Economy Revisited: Price Setting and Exchange Rate Flexibility," NBER Working Paper No. 7655 (Cambridge, Massachusetts: National Bureau of Economic Research).

Dixit, A., and J. Stiglitz, 1977, "Monopolistic Competition and Optimum Product Diversity," American Economic Review, Vol. 67, pp. 297-308.

Dotsey, M., Robert King, and A. Wolman, 1999, "State Dependent Pricing and the Dynamics of Business Cycles," Quarterly Journal of Economics, Vol. 114, pp. 655-90.

Erceg, C., Dale Henderson, and Andrew Levin, 2000, "Optimal Monetary Policy with Staggered Wage and Price Contracts," Journal of Monetary Economics, Vol. 46, pp. 281-313.

Fuhrer, J., 1997, "A Comment on Optimization Based Econometric Framework for the Evaluation of Monetary Policy," NBER Macroeconomics Annual 1997 (Cambridge, Massachusetts: MIT Press).

— 2000, "Habit Formation in Consumption and its Implications for Monetary Policy Models," American Economic Review, Vol. 90, pp. 367-90. 
Gali, Jordi, Mark Gertler, and J. David Lopez-Salido, 2002 "Markups, Gaps, and the Welfare Costs of Business Fluctuations," NBER Working Paper No. 8850 (Cambridge, Massachusetts: National Bureau of Economic Research).

Ghosh, J., and P. Masson, 1988, "International Policy Coordination in a World with Model Uncertainty," IMF Staff Papers, Vol. 35 (Washington, DC: International Monetary Fund).

—, 1991, "Model Uncertainty, Learning and the Gains from Coordination," American Economic Review, Vol. 81.

—, 1994, "Economic Cooperation in an Uncertain World," (Cambridge, Massachusetts: Blackwell).

Goodfriend, M., and Robert King, 2000, “The Case for Price Stability,” (unpublished; Virginia: FRB of Richmond; Massachusetts: Boston University).

Hall, Robert, 1988, "Intertemporal Substitution in Consumption," Journal of Political Economy, Vol. 96, No. 2, pp. 339-57.

Hamada, Koichi, 1974, "Alternative Exchange Rate Systems and the Interdependence of Monetary Policies," in National Monetary Policies and the International Financial System, ed. by Robert Aliber (Chicago: University of Chicago Press).

- 1976, “A Strategic Analysis of Monetary Interdependence," Journal of Political Economy, Vol. 84, No. 4, pp. 677-700.

_ 1979, "Macroeconomic Strategy and Coordination under Alternative Exchange Rates," in International Economic Policy: Theory and Evidence, ed. by R. Dornbusch and J. Frenkel (Baltimore: John Hopkins University Press).

Hansen, G., 1985, “Indivisible Labor and the Business Cycle,” Journal of Monetary Economics, Vol. 16, pp. 309-27.

Harrigan, J., 1976, “OECD Imports and Trade Barriers in 1983," Journal of International Economics, Vol. 35, pp. 91-112.

Kim, Jinill, and Sunghyun Kim, 1999, "Spurious Welfare Reversals in International Business Cycles Models," forthcoming, Journal of International Economics.

Kollmann, Robert, 2002, "Monetary Policy in the Open Economy: Effects on Welfare and Business Cycles," Journal of Monetary Economics, Vol.49, pp. 989-1015. 
Lucas, Robert, 1987, Models of Business Cycles (Blackwell, Oxford).

Mankiw, N. Gregory, and Lawrence H. Summers, 1986, "Money Demand and the Effects of Fiscal Policies," Journal of Money, Credit and Banking, Vol. 18, pp. 415-29.

McKibbin, W., 1997, "Empirical Evidence on International Economic Policy Coordination," in Handbook of Comparative Economic Policies, Vol.5, ed. by M. Fratianni, D. Salvatore, and J. Von Hagen (Westport: Greenwood Press).

McCallum, B., and E. Nelson, 2001, "Monetary Policy for an Open Economy: an Alternative Framework with Optimizing Agents and Sticky Prices," NBER Working Paper No. 8175 (Cambridge, Massachusetts: National Bureau of Economic Research).

Obstfeld, M., and K. Rogoff, 1995, "Exchange Rate Dynamics Redux," Journal of Political Economy, Vol. 103, pp. 624-60.

—_ 1998, "Risk and the Exchange Rate," NBER Working Paper No. 6694 (Cambridge, Massachusetts: National Bureau of Economic Research).

_ 2002, "Global Implications of Self-oriented National Rules," Quarterly Journal of Economics, Vol. 117, pp. 503-35.

Oudiz, Gilles, and J. Sachs, 1984, "Macroeconomic Policy Coordination Among the Industrial Economies," Brookings Papers on Economic Activity, Vol. 1 (Washington, DC: The Brookings Institution Press).

__ 1985, "International Policy Coordination in Dynamic Macroeconomic Games," ed. by M. Buiter and R. Marston.

Pappa, Evi, 2002, "Should the ECB and the FED Cooperate? Optimal Monetary Policy in a Two-Country World," (unpublished; London: London School of Economics and Political Science).

Rogoff, Kenneth, 1985, "Can International Monetary Cooperation be Counterproductive?" Journal of International Economics, Vol. 18, pp. 199-217.

Rotemberg, J., and M. Woodford, 1998, "An Optimization-based Econometric Framework for the Evaluation of Monetary Policy," in NBER Macroeconomic Annual, ed. by B. Bernanke and J. Rotemberg (Cambridge: MIT Press).

Scmitt-Grohe, S., and Martin Uribe, 2001, "Solving Dynamic General Equilibrium Models Using a Second-order Approximation to the Policy Function," CEPR Discussion Paper No. 2963 (London: Centre for Economic Policy Research). 
—_, 2002, "Closing Small Open Economy Models," NBER Working Paper 9270 (Cambridge, Massachusetts: National Bureau of Economic Research).

Sims, C., 2003, "Second-order Accurate Solution of Discrete Time Dynamic Equilibrium Models," (unpublished; Princeton, New Jersey: Princeton University).

Smets, Frank, and Raf Wouters, 2002, "Openness, Imperfect Exchange Rate Pass-through and Monetary Policy," ECB Working Paper No. 128 (Frankfurt, Germany: European Central Bank).

Sutherland, Alan, 2002a, "A Simple Second-order Solution Method for Dynamic General Equilibrium Models," (unpublished; Fife, Scotland: University of St. Andrews).

—_ 2002b, "International Monetary Policy Coordination and Financial Market Integration," (unpublished; Fife, Scotland: University of St. Andrews).

Trefler, D., and H. Lai, 1999, "The Gains from Trade: Standard Errors with the CES Monopolistic Competition Model," (unpublished; Toronto, Canada: University of Toronto).

Weerapana, Akila, 2000, "The Performance of Monetary Policy Rules in a Backward Looking Model of the U.S. and the EMU," (unpublished; Wellesley, Massachusetts: Wellesley College).

Woodford, Michael, 1996, "Control of the Public Debt: a Requirement for Price Stability," NBER Working Paper No. 5684 (Cambridge, Massachusetts: National Bureau of Economic Research).

—_, 2001, "Inflation Stabilization and Welfare," NBER Working Paper No. 8071 (Cambridge, Massachusetts: National Bureau of Economic Research).

Yun, Tack, 1996, "Nominal Price Rigidity, Money Supply Endogeneity and Business Cycles," Journal of Monetary Economics, Vol. 37, pp. 345-70. 